\title{
Role of P2X7 Receptors in Immune Responses During Neurodegeneration
}

\author{
Ágatha Oliveira-Giacomelli1t, Lyvia Lintzmaier Petiz ${ }^{1+}$, Roberta Andrejew ${ }^{1+}$, \\ Natalia Turrini ${ }^{1+}$, Jean Bezerra Silva ${ }^{1 t}$, Ulrich Sack ${ }^{2}$ and Henning Ulrich ${ }^{1,2 *}$ \\ 'Department of Biochemistry, Institute of Chemistry, University of São Paulo, São Paulo, Brazil, ${ }^{2}$ Institute of Clinical \\ Immunology, Medical Faculty, University of Leipzig, Leipzig, Germany
}

\section{OPEN ACCESS}

Edited by:

Robson Xavier Faria,

Oswaldo Cruz Institute, Oswaldo Cruz Foundation (Fiocruz), Brazil

Reviewed by:

Bogdan O. Popescu, Carol Davila University of Medicine and Pharmacy, Romania

Gunnar P. H. Dietz,

University of Göttingen, Germany

Ben J. Gu,

University of Melbourne, Australia Sahil Adriouch,

Université de Rouen, France

*Correspondence:

Henning Ulrich

henning@iq.usp.br

${ }^{\dagger}$ These authors have contributed equally for this work

Specialty section:

This article was submitted to

Cellular Neuropathology,

a section of the journal

Frontiers in Cellular Neuroscience

Received: 01 February 2021

Accepted: 26 April 2021

Published: 26 May 2021

Citation:

Oliveira-Giacomelli Á, Petiz LL, Andrejew R, Turrini N, Silva JB,

Sack $U$ and Ulrich $H$ (2021) Role of P2X7 Receptors in Immune Responses During

Neurodegeneration

Front. Cell. Neurosci. 15:662935. doi: 10.3389/fncel.2021.662935
P2X7 receptors are ion-gated channels activated by ATP. Under pathological conditions, the extensive release of ATP induces sustained P2X7 receptor activation, culminating in induction of proinflammatory pathways with inflammasome assembly and cytokine release. These inflammatory conditions, whether occurring peripherally or in the central nervous system (CNS), increase blood-brain-barrier (BBB) permeability. Besides its wellknown involvement in neurodegeneration and neuroinflammation, the P2X7 receptor may induce BBB disruption and chemotaxis of peripheral immune cells to the CNS, resulting in brain parenchyma infiltration. For instance, despite common effects on cytokine release, P2X7 receptor signaling is also associated with metalloproteinase secretion and activation, as well as migration and differentiation of $\mathrm{T}$ lymphocytes, monocytes and dendritic cells. Here we highlight that peripheral immune cells mediate the pathogenesis of Multiple Sclerosis and Parkinson's and Alzheimer's disease, mainly through $T$ lymphocyte, neutrophil and monocyte infiltration. We propose that P2X7 receptor activation contributes to neurodegenerative disease progression beyond its known effects on the CNS. This review discusses how P2X7 receptor activation mediates responses of peripheral immune cells within the inflamed CNS, as occurring in the aforementioned diseases.

\section{Keywords: P2X7 receptors, neurodegeneration, peripheral immune system, blood brain barrier, microglia}

\section{INTRODUCTION}

Purinergic receptors participate in the primordial cell signaling mechanism triggered by adenosine tri $^{-}$and diphosphate (ATP and ADP, respectively) and adenosine molecules. Purines are involved in several cellular functions through their binding to P1 and P2 receptors. P2 receptors are further divided into P2Y (metabotropic) and P2X (ionotropic) receptors, which include the P2X7 receptor (Burnstock, 2018), composed of two transmembrane domains and assembled as trimeric receptors. When activated, P2X receptors allow the efflux of $\mathrm{K}^{+}$

Abbreviations: AD, Alzheimer's disease; ATP, adenosine triphosphate; BBB, blood-brain barrier; BBG, Brilliant Blue G; CD4, cluster of differentiation 4; CD8, cluster of differentiation 8; CD62L, cluster of differentiation $62 \mathrm{~L}$, also known as L-selectin; CCL3, chemokine (C-C motif) ligand 3; CNS, central nervous system; EAE, experimental autoimmune encephalomyelitis; ECs, endothelial cells; IL-1 $\beta$, interleukin 1 $\beta$; LPS, lipopolysaccharide; MCP-1, monocyte chemoattractant protein-1; MDMA, 3,4-methyllenedioxymethamphetamine; MS, multiple sclerosis; MMP-9, matrix metalloproteinases 9; NLRP3, NOD-like receptor protein 3; NO, nitric oxide; PD, Parkinson's disease; ROS, reactive oxygen species; TNF- $\alpha$, tumor necrosis factor $\alpha$. 
and influx of $\mathrm{Na}^{+}$and $\mathrm{Ca}^{2+}$ (Bartlett et al., 2014). Besides being involved in several physiological processes, such as neurotransmitter release and proliferation, survival and activation of microglia and peripheral immune cells, P2X7 receptors are activated at extracellular ATP concentrations above homeostatic concentrations (0.05-1 mM) (Burnstock and Kennedy, 2011). The increased concentration of extracellular ATP, instead of causing desensitization of the receptor, as it occurs in other receptors, induces cell death through the opening of membrane pores. These pores increase membrane permeability to hydrophilic solutes and allow the passage of molecules of up to 900 Da which can impair homeostasis (Di Virgilio et al., 2018). ATP hydrolysis and consequent decrease in its concentration promotes the closure of these pores (Di Virgilio, 2007).

The P2X7 receptor presents several alternative splicing isoforms. In humans, only the $\mathrm{A}$ and $\mathrm{B}$ isoforms form functional receptors. The $\mathrm{P} 2 \mathrm{X} 7 \mathrm{~A}$ is the full-length isoform and the $\mathrm{P} 2 \mathrm{X} 7 \mathrm{~B}$ isoform is a truncated form. The B isoform, although assembled as a functional channel, is not able to form large pores (Adinolfi et al., 2010). P2X7 receptor activation is tightly involved in pro-inflammatory events, involving several cytokines. As illustrated in Figure 1A, P2X7 receptor activation induces $\mathrm{K}^{+}$efflux and NLRP3 inflammasome assembly, cleaving pro-caspase- 1 into active caspase-1. Caspase- 1 is responsible for converting pro-IL-1 $\beta$ into mature IL-1 $\beta$, cleaving the autoinhibitory domain of Gasdermin-D-C (free carboxi terminal ending), and subsequently creating its Gasdermin-D-N (free amino terminal ending) active form (He et al., 2015; Lieberman et al., 2019). Gasdermin-D-N oligomerizes upon interaction with membrane phospholipids generates a membrane pore responsible for the release of interleukins of the interleukin1 family (IL-1), such as IL-1 $\beta$ and IL-18, worsening the inflammatory scenario (Liu et al., 2016). In addition to their liberation through the Gasdermin-D pore, cytokines of the IL1 family may also be released into the extracellular space by microvesicles, exosomes or endosomes (Giuliani et al., 2017). In addition, the NLRP3/gasdermin-D pathway is also responsible for inducing membrane permeabilization and pyroptose. This pathway promotes an inflammatory type of cell death that releases intracellular content, acting as damage associated molecular pattern, exacerbating inflammatory status (Sborgi et al., 2016; Voet et al., 2019). IL-1 $\beta$ triggers formation of other proinflammatory factors, such as reactive oxygen species (ROS), nitric oxide (NO), and tumor necrosis factor $\alpha$ (TNF- $\alpha$ ) (Giuliani et al., 2017).

ATP binding to P2X7 receptors activates the NLRP3 inflammasome, inducing cell death and tissue damage and the release of more ATP, stimulating microglial cells and recruiting peripheral immune cells. At this point, ATP release/P2X7 receptor activation/apoptosis axis act on a positive feedback loop, greatly contributing to the neurodegenerative process in a continuous manner. Immune cells release more cytokines and chemokines, exacerbating the inflammatory scenario and activating pro-apoptotic cascades culminating in cell death. Furthermore, P2X7 receptor activation increases glutamate secretion, which could aggravate glutamate excitotoxicity observed in neurodegenerative diseases (Spérlagh et al., 2002;
Cho et al., 2010). The neuroinflammatory process observed in neurodegenerative diseases is mediated by cells of the peripheral immune system and by resident microglial cells (Prinz and Priller, 2017). Neuroinflammation broadly refers to immune processes taking place in the central nervous system (CNS) that are elicited by a stimulus, such as infection, physiological stress or neurological disease, among others. The released proinflammatory factors induce increased blood-brain barrier (BBB) permeability and facilitate peripheral immune cells neuroinvasion (Prinz and Priller, 2017). A temporary stimulus tends to be beneficial, but if it persists, it may affect CNS homeostasis, synaptic transmission, and plasticity. This seems to be the case for neurodegenerative diseases, where continuous activation of immune cells promotes exacerbated inflammation, leading to cognitive decline (Lee et al., 2010). The entire process that culminates in the neuroinvasion of peripheral immune cells, as well as the neuroinflammation itself, has stages modulated by the $\mathrm{P} 2 \mathrm{X} 7$ receptor (Figure 1B). The participation of the $\mathrm{P} 2 \mathrm{X} 7$ receptor in innate immune responses stimulating the inflammasome in the peripheral immune system (Ratajczak et al., 2020), as well as in the brain contributing to neuroinflammation and neuropsychiatric diseases (Ratajczak et al., 2019) has been proposed.

This review provides evidence for the participation of the P2X7 receptor in neuroinflammatory processes mediated by peripheral and resident immune cells. While roles of $\mathrm{P} 2 \mathrm{X} 7$ receptors in neuroinflammation and neurodegeneration have been extensively discussed in the literature, the current knowledge of possible involvement of these receptors in neuroinvasion by peripheral immune cells is scarce.

\section{NEUROINVASION OF PERIPHERAL IMMUNE CELLS: BLOOD-BRAIN-BARRIER PERMEABILITY}

The BBB is a highly selective barrier that allows the communication between the CNS and the peripheral system, regulating molecule transport into and from the brain and leading to a fine tune modulation of microenvironment homeostasis (Zlokovic, 2011; Zhao et al., 2015; Montagne et al., 2017). Its major functions include entry control of pathogens, blood cells and neurotoxic components from the bloodstream into the $\mathrm{CNS}$. The $\mathrm{BBB}$ protects the $\mathrm{CNS}$ from peripheral circulation and is composed of endothelial cells (ECs), astrocytes and pericytes that are linked via different connections, such as tight junctions, tricellular junctions and adherent junctions. The interplay between these cells is fundamental to BBB function. The set of morphological and molecular interactions between these cells is called neurovascular unit (NVU), which conducts the maintenance of CNS homeostasis through intercellular signaling and physical communication (Iadecola, 2017; Sweeney et al., 2019).

Cerebral ECs present tight junction proteins bonded to the cytoskeleton, such as claudin-5 and occludin, which participate 

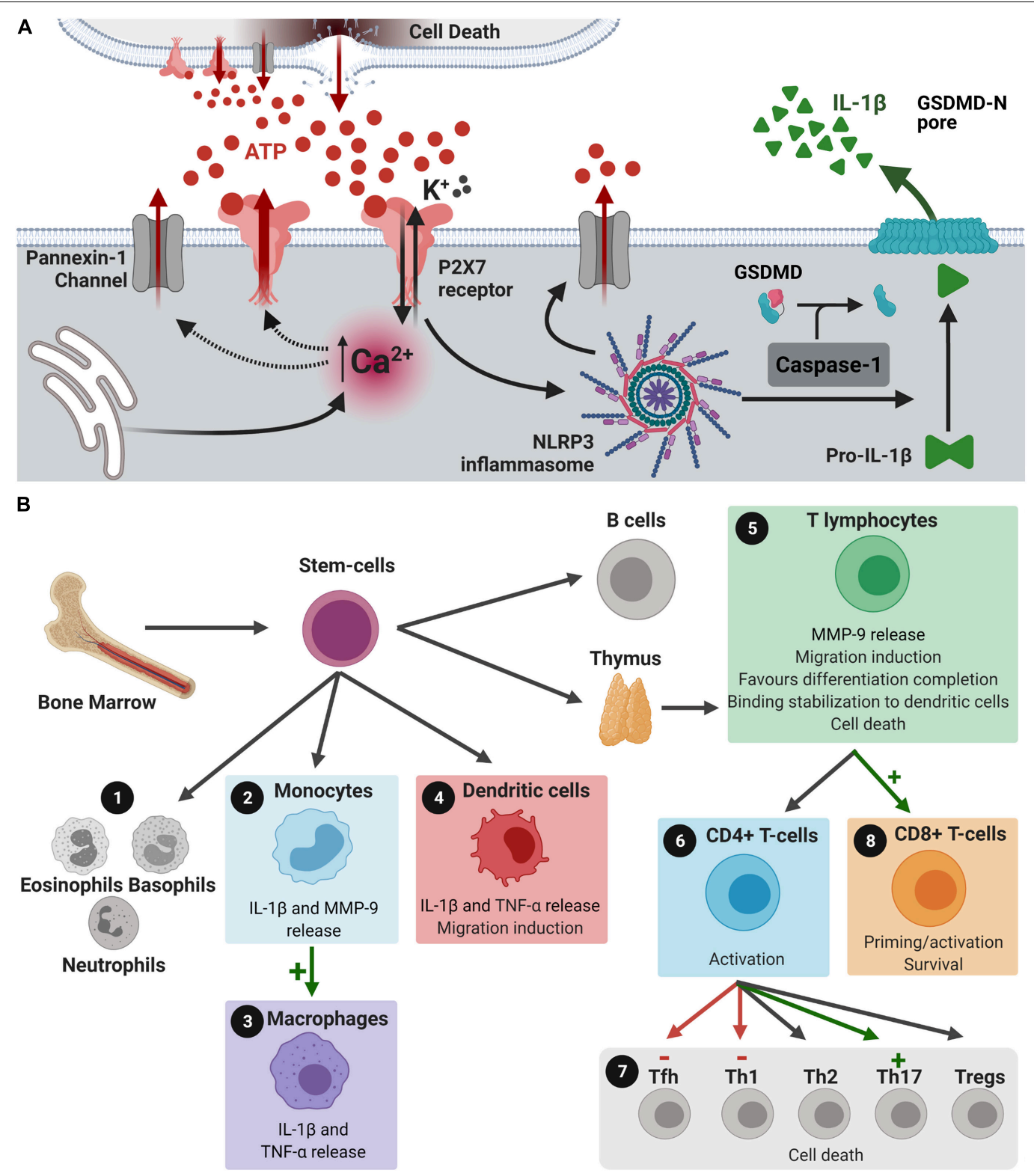

FIGURE 1 | P2X7 receptors in peripheral immune cells and IL-1 $\beta$ release. (A) Dying cells release ATP. ATP binds and activates P2X7 receptors, which induces Ca ${ }^{2+}$ influx and $\mathrm{K}^{+}$efflux. Intracellular $\mathrm{Ca}^{2+}$ concentration increase induces the formation of large pores by P2X7 receptors and pannexin-1, both allowing the release of more ATP. This results in augmented extracellular ATP concentration and increased activation of P2X7 receptors, providing positive feedback effects. ${ }^{+}$efflux $^{-1}$ induces NLRP3 inflammasome assembly and the formation of more pannexin-1 channels. NLRP3 inflammasome assembly activates caspase-1, which cleaves pro-IL-1 $\beta$ into IL-1 $\beta$ and promotes its release. Caspase-1 also cleaves the inhibitory gasdermin (GSDMD)-D-C into the reactive GSDMD-D-N, that interacts with membrane phospholipids to form a pore that allows IL-1 $\beta$ release. This release could also occur through microvesicles, exosomes or endosomes (not shown). (B) Bone marrow stem cells can differentiate into (1) eosinophils, basophils, neutrophils, (2) monocytes, (4) dendritic cells, (5) T and B lymphocytes. (2) Activation of the P2X7 receptor in monocytes induces the release of MMP-9, which can induce disruption of BBB, and IL-1 $\beta$ liberation. (3,4) P2X7 receptor activation induces the differentiation of monocytes into macrophages and stimulates the release of IL-1 $\beta$ and TNF- $\alpha$ from monocytes, macrophages, and dendritic cells. (4) Released IL-1 $\beta$ stimulates the migration of dendritic cells. (5) In T lymphocytes, P2X7 receptor activation may: release MMP-9, induce the migration of these cells, favor differentiation into $\mathrm{CD}^{+}$or $\mathrm{CD} 8^{+}$cells before leaving the thymus, stabilizes its binding to dendritic cells and promote cell death, if necessary. IL-1 $1 \beta$ released by dendritic cells through P2X7 receptor stimulation activates CD4 ${ }^{+}$cells and (6) differentiation of these cells into T helper (Th) 1 and 17 , and T follicular helper cells (Tfh). (7) Activation of P2X7 receptors in $\mathrm{CD} 8^{+}$cells promotes activation and survival of these cells, while IL- $1 \beta$ released by dendritic cells primes $\mathrm{CD} 8^{+}$cells. (8) P2X7 receptor expression is essential for differentiation of T cells into CD8 ${ }^{+}$cells. Created with BioRender.com.

in paracellular communication processes of BBB with distinct functions (Engelhardt and Liebner, 2014; Anderson and Van Itallie, 1995). The disruption in claudin-5 leads to increased
BBB permeability and high mortality in mice, and occludin disruption induces brain calcification (Saitou et al., 2000; Nitta et al., 2001). Destabilization of BBB cellular organization can 
be found in cerebral injuries (Shlosberg et al., 2010) caused by increased levels of inflammatory cytokines and ROS (Gasche et al., 2001; Katsu et al., 2010). These proinflammatory factors activate matrix metalloproteinases (MMPs) and zinc-calcium dependent endopeptidases, which can degrade proteins of the extracellular matrix and tight junctions in the ECs (Vecil et al., 2000; Liu and Rosenberg, 2005; Katsu et al., 2010; Gottschall, 2016).

Proposed roles of ATP/P2X7 signaling in tight junction impairment processes are presented in Figure 2A. The release of IL-1 $\beta$ following P2X7 receptor activation triggers the production of MMP-9, degrading occludins and disrupting BBB integrity, as observed in human and rat in vitro models, as well as in vivo in mice (Harkness et al., 2000; Mori et al., 2002; Gu and Wiley, 2006; Rosenberg, 2009). Similar results were observed in human EC and astrocyte co-culture, simulating the BBB in vitro. Treatment with the P2X7 receptor agonist BzATP caused significant increase in IL-1 $\beta$ and MMP-9 levels, resulting in decreased concentrations of tight junction proteins, such as occludin (Yang et al., 2016). These results indicate that the degradation of tight junction proteins induced by ATP/P2X7 receptor signaling is strongly associated with IL-1 $\beta$ receptors, which plays a fundamental role in BBB dysfunction (Yang et al., 2016).

Pericytes are the other cell type essential for optimal BBB formation, function and maintenance (Bell et al., 2010; Daneman et al., 2010; Nisancioglu et al., 2010). They alter EC behavior through activity modulation of transporters and expression of ion channels and junction proteins (Rucker et al., 2000; Franco et al., 2011; Bai et al., 2015). ECs and pericytes are the cells from the NVU with the strongest contact, interacting through peg-and-socket junctions. This interaction allows the transport of nutrients and metabolic signaling to the CNS. Both cell types are inserted in the basement membrane, with proteins that are crucial to BBB integrity and stability. The basement membrane is a unique form of extracellular matrix, known as the BBB noncellular component. It comprises four major types of proteins: laminin, nidogen, perlecan, and collagen IV (Nisancioglu et al., 2010; Baeten and Akassoglou, 2011). Involvement of the P2X7 receptor in degradation of collagen IV by the neurotoxic compound 3,4-methyllenedioxymethamphetamine (MDMA) was demonstrated in rats. Administration of MDMA increased levels of P2X7 receptor expression in activated microglia cells. This effect was accompanied by enhanced proteolytic activities of hippocampal MMP-3 and MMP-9, resulting in laminin and collagen IV degradation (Figure 2A; Rubio-Araiz et al., 2014). Associated with these results, leakage of IgG into the brain parenchyma was found, which indicates higher BBB permeability. Remarkably, treatment with Brilliant Blue G (BBG, P2X7 receptor antagonist), prevented P2X7 receptor expression increase in rat hippocampus and subsequent effects observed by MDMA administration (Rubio-Araiz et al., 2014). Thus, that data suggests that $\mathrm{P} 2 \mathrm{X} 7$ receptor activation increases BBB permeability triggered by MDMA through stimulation of MMPs. Recently, the immune system has been suggested as a new target of pericytes. Pericytes can modulate phagocytosis, adhesion molecules expression, stimulate neutrophil transmigration and generation of proinflammatory mediators, as inducible nitric oxide synthase (iNOS), ROS and cyclooxygenase (COX). Thus, it is suggested that pericytes participate in neuroinflammation processes (Hurtado-Alvarado et al., 2014; Pieper et al., 2014; Wang and Sanz, 2016; Rustenhoven et al., 2017).

Astrocytes are also important for BBB maintenance. The astrocyte end-foot covers ECs and communicates with them through gap and peg-and-socket junctions (Kim et al., 2009; Bonkowski et al., 2011; Winkler et al., 2011). They are a source of signaling molecules that regulate NVU functioning (Engelhardt and Liebner, 2014). Rats submitted to intracerebral hemorrhage presented increased P2X7 receptor expression in astrocytes and ECs. This scenario was succeeded by neuronal death, neurobehavioral and neurofunctional deficits, cerebral edema, increased RhoA (known to regulate the formation of adhesions and stress fibers) expression and a decreased expression of structural endothelial proteins, such as occludin and vascular endothelial cadherin (Mueller, 2014). Treatment with A438079, a selective P2X7 receptor inhibitor, or P2X7 receptor gene knockdown reduced these phenotypes. Additionally, this treatment also prevented parenchymal leakage induced by intracerebral hemorrhage (Zhao et al., 2016).

The $\mathrm{BBB}$ is also composed of perivascular macrophages (PVMs), which are resident CNS macrophages located in the perivascular space (or Virchow-Robin space). Despite being under debate, PVMs seem to originate from the yolk sac similarly to microglial cells, although they are distinguished by the expression of specific proteins (Bechmann et al., 2001; Goldmann et al., 2016). The exact role of brain PVMs in the BBB permeability remains unknown, but their phagocytic activity selectively restricts the crossing of serum proteins and macromolecules into the brain parenchyma (Willis et al., 2007). Additionally, PVMs have an important role protecting the brain during bacterial and viral infections (Polfliet et al., 2001; Filipowicz et al., 2016). These cells connect the peripheral immune system with the CNS through the regulation of neutrophil (Polfliet et al., 2001), T cell (Tran et al., 1998) and leukocyte infiltration by MMP-2 and MMP-9 activity modulation (Figure 2A; Agrawal et al., 2006; Bechmann et al., 2007). Under conditions of systemic immune activation, PVMs regulate the hypothalamo-pituitary-adrenal (HPA) axis, prostaglandin expression, controlling inflammation in rat and mouse models (Serrats et al., 2010; Vasilache et al., 2015). These features are relevant for CNS diseases. In fact, it is hypothesized that PVMs may exert protective effects in the initial phases of CNS diseases, avoiding disease progression and misfolded protein spreading; however, repeated PVM activation might result in detrimental and progressive effects of CNS diseases (Koizumi et al., 2019). P2X7 receptor expression in macrophages and its role in inflammation and immunity is widely recognized, as discussed below. Noteworthy, P2X7 receptor stimulation of the NLRP3 inflammasome pathway is essential in macrophage polarization (Di Virgilio et al., 2017; Savio et al., 2018). However, the P2X7 receptor was not yet investigated in PVMs, evidencing a relevant gap in the field. Considering the control of inflammation by PVMs, the surveillance of immune infiltrating cells, the modulation of macrophage polarization and the role of the $\mathrm{P} 2 \mathrm{X} 7$ receptor in CNS diseases, we propose that $\mathrm{P} 2 \mathrm{X} 7$ receptors 


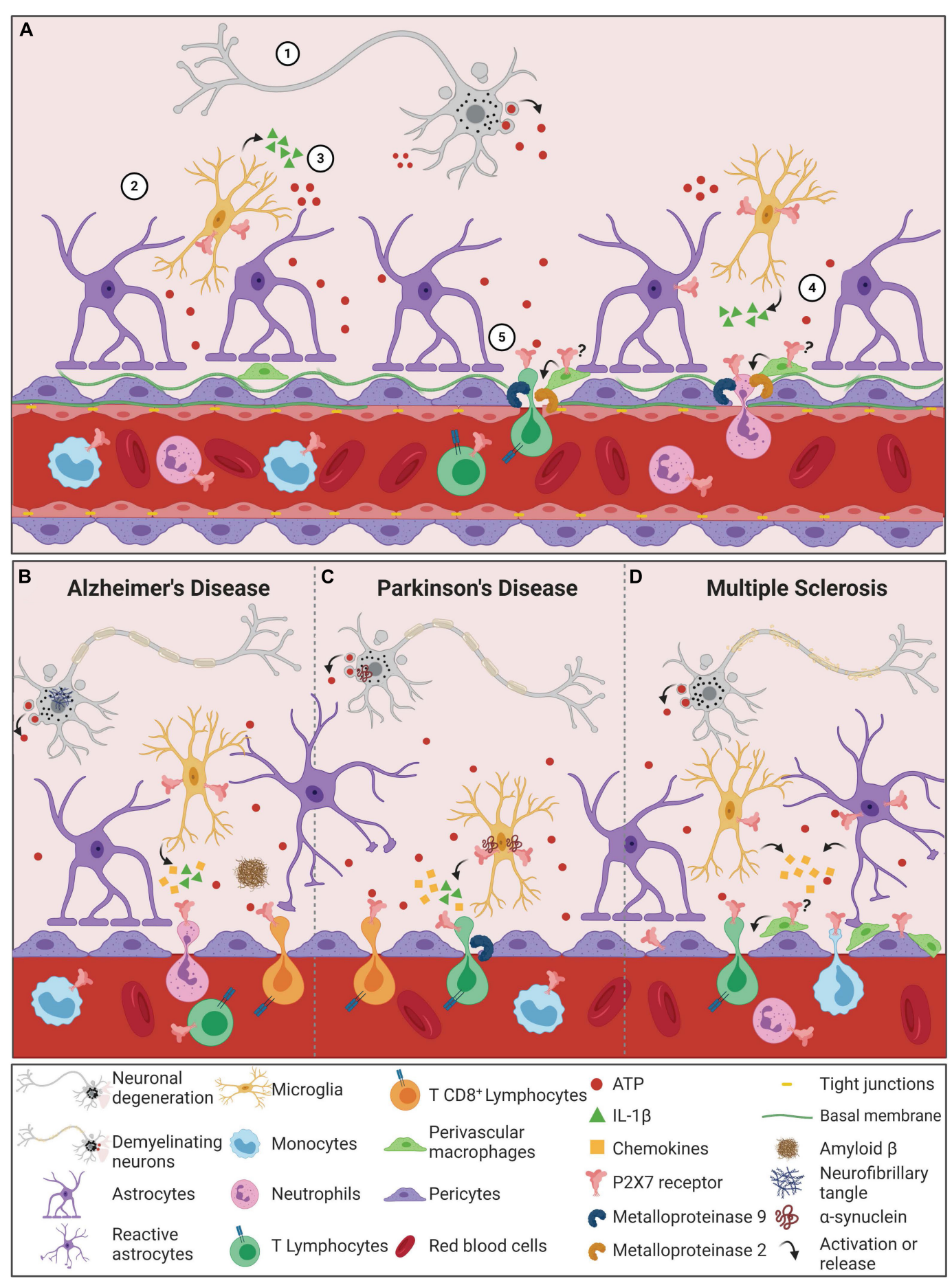

FIGURE 2 | The P2X7 receptor in the process of Blood-Brain Barrier permeabilization during neurodegenerative diseases. (A) Blood-Brain Barrier permeabilization through P2X7 receptor signaling begins with cellular damage, which triggers cell death and consequently ATP release into the CNS microenvironment (1). ATP content above physiologic ranges activates P2X7 receptors in microglial cells (2), which in turn leads to the production and release of IL-1 $1 \beta$ and other cytokines and chemokines (3). Moreover, the active ATP/P2X7 receptor pathway augments metalloproteinase (MMP) activities, causing TJ and BM protein degradation and consequently BBB destabilization (4). The outcome of these combined events is the peripheral immune cell invasion of the CNS. Since T cells and neutrophils express P2X7 receptors, the amount of ATP released by the damaged cells can also activate this receptor in these cells. The result is the shedding activation of adhesion proteins and the production and release of cytokines and MMPs, promoting an inflammatory and invasive feedback mechanism (5). In neurodegenerative diseases, the neuronal death process induces the release of high concentrations of ATP into the extracellular milieu. (B) In AD pathogenesis, ATP binds to P2X7 receptors that are overexpressed in microglial cells. The microglial activation depends on P2X7 receptor expression/activity to react against A $\beta$ peptides. P2X7 


\section{FIGURE 2 | Continued}

receptor stimulates the release of IL- $1 \beta$ and chemokines that contribute to increased BBB permeability, resulting in chemotaxis of neutrophil and CD8 ${ }^{+}$cells. (C) In PD, $\alpha$-synuclein aggregates contribute to dopaminergic neuronal death, increasing ATP levels and P2X7 overactivation. $\alpha$-synuclein can bind to P2X7 receptors expressed in microglial cells. Both $\alpha$-synuclein and P2X7 receptors are associated with increased release of IL-1 $\beta$ and chemokines, indicating an enhanced neuroinflammatory scenario in PD. This IL-1 $\beta$ secretion is associated with induction of MMP-9 release, resulting in BBB dysfunction. Under condition of BBB dysfunction and increased chemokine levels, $T$ cells are chemoattracted and infiltrate brain parenchyma. T cells can recognize $\alpha$-synuclein epitopes, release high amounts of ATP and present upregulation of P2X7 receptor activity, contributing to PD worsening. (D) The demyelinating character of MS is also associated with increased ATP levels and P2X7 receptor overactivation. P2X7 receptor expression and activity are upregulated in reactive astrocytes and contribute to the release of chemokines and peripheral immune cell chemotaxis. Pericytes also express P2X7 receptors that mediate the interaction between endothelial cells and pericytes and contribute to BBB integrity. Increased numbers of perivascular macrophages are associated with disease progression, and P2X7 receptor functions in this process remain unknown. MS exhibits infiltrating T cells and monocytes, expressing P2X7 receptors that contribute to the autoimmune attack and disease progression. (?) Hypothesis of P2X7 receptor involvement in perivascular macrophages, yet to be elucidated. Created with BioRender.com.

regulate the physiological and pathological functions of PVMs, assisting BBB permeability shifts.

Relevant for this topic, the infiltration of peripheral immune cells through the BBB is a core feature of its disruption. Interactions between adhesion proteins expressed by ECs, integrins and selectins expressed by peripheral cells are necessary for infiltration (Greenwood et al., 2002; Nisancioglu et al., 2010). It is known that trans endothelial migration of peripheral immune cells depends on various factors, such as the shedding of CD62L and CD21 membrane proteins. Brain injuries cause cellular damage and, consequently, higher levels of extracellular ATP (Volonte et al., 2003; Melani et al., 2005). This event is often associated with increased BBB permeability and invasion of peripheral cells in the CNS. Thus, the participation of $\mathrm{P} 2 \mathrm{X} 7$ as a mediator in this trans endothelial migration signaling pathway has been investigated. It has been suggested that P2X7 receptor mediates the participation of ROS and extracellular ATP in the induction of MMPs activity, causing CD62L shedding in B lymphocytes (Foster et al., 2013). Similar assays using treatments with P2X7 receptor agonists and antagonists confirmed that induction of CD62L and CD21 shedding in T cells, B cells and neutrophils are mediated by the P2X7 receptor (Jamieson et al., 1996; Gu et al., 1998; Sengstake et al., 2006). Altogether, these data propose a different pathway by which the P2X7 receptor modulates immune functions in an indirect way, having as target the peripheral immune cells that penetrate the CNS toward injury areas.

\section{PERIPHERAL IMMUNE CELLS}

The peripheral immune system is composed of lymphocytes, including T-, B-, and natural killer cells, neutrophils and monocytes/macrophages (Figure 1B). During CNS injury, peripheral innate (monocytes) and adaptative (B and $\mathrm{T}$ ) immune cells can infiltrate the CNS according to the extent of the BBB permeability (Prinz and Priller, 2017). The P2X7 receptor is suggested to be involved in several actions exerted by these cells (Figure 1B). For instance, a single nucleotide polymorphism in the P2X7 receptor gene (Glu496Ala) that induces lossof-function was identified in humans. This polymorphism protected whole blood samples against cytotoxic effects of high concentrations of ATP (Wesselius et al., 2012) and reduced IL-1 $\beta$ release by monocytes (Sluyter et al., 2004). Additionally, P2X7 receptor activation induced the release of MMP-9 by peripheral blood mononuclear cells and in both purified monocyte and T-cell populations ( $\mathrm{Gu}$ and Wiley, 2006), indicating that immune cells may release factors that also contribute to BBB disruption, favoring brain invasion. Dendritic cells, responsible for activating T-cells by positioning them in the surface of cells in contact with pathogens, migrate and release interleukins and pro-inflammatory factors upon P2X7 receptor activation, determining T-cell polarization (Rivas-Yáñez et al., 2020). Once in the brain, these factors could increase neuroinflammation, worsening brain injury in neurodegenerative diseases.

\section{Monocytes}

In the healthy brain, monocytes reside in the endovascular space and do not invade brain parenchyma (Prinz and Priller, 2017). However, in the diseased brain, these cells migrate to injured areas and differentiate into macrophages with high phagocytic and inflammatory activities, which in some cases may result in disease worsening and autoimmune attack (Yamasaki et al., 2014). Although there is no change in P2X7 receptor gene expression in the differentiation process, the amount of surface labeled P2X7 receptors increase (Gudipaty et al., 2001). As recently shown by single-cell RT-PCR, $90 \%$ of human monocytederived macrophages present $\mathrm{P} 2 \mathrm{X} 7$ receptor gene expression. Sixty nine\% of these cells present ATP-evoked P2X7 receptor currents (Vargas-Martínez et al., 2020).

$\mathrm{P} 2 \mathrm{X} 7$ receptor activation in monocyte/macrophages is involved in pro-inflammatory effects. Activation of monocytic P2X7 receptors induces NLRP3 inflammasome assembly and interleukin secretion in M1 macrophages (Gu and Wiley, 2018). Interestingly, studies suggest that pore formation mediated by P2X7 receptors is independent of pannexin-1 actions (Alberto et al., 2013). However, anti-inflammatory effects of the P2X7 receptor were proposed in M2 macrophages, based on release induction of molecules involved in inflammation resolution (De Torre-Minguela et al., 2016). Moreover, in these cells, modulation of phagocytic activity by the $\mathrm{P} 2 \mathrm{X} 7$ receptor and its beneficial effects at physiological conditions are under investigation. It is proposed that, in the presence of ATP at low concentrations, the macrophage P2X7 receptor acts as a scavenger receptor, recognizing and engulfing apoptotic cells ( $\mathrm{Gu}$ and Wiley, 2018; Zumerle et al., 2019). This process occurs due to the formation of a complex between the P2 X 7 receptor and non-muscle myosin IIA (expressed by resting macrophage), which directly binds to the extracellular domain of apoptotic cells. The presence of high 
ATP concentrations promotes dissociation of this complex and inhibits phagocytic activity (Gu et al., 2010). Increased P2X7 receptor expression in human macrophages was correlated with rapid bead engulfment in vitro, impaired by blocking P2X7 receptor expression (Gu et al., 2011). Upon increased ATP levels, P2X7 receptor activation inhibits this phagocytic activity and exerts pro-inflammatory effects (Wiley and Gu, 2012; Gu and Wiley, 2018). Altogether, the P2X7 receptor plays essential roles in monocyte/macrophage differentiation, activation/polarization and function, both in physiological and pathological conditions.

\section{T Cells}

$\mathrm{T}$ cells are a subtype of lymphocytes and comprehend $\mathrm{CD} 4^{+}$helper and $\mathrm{CD} 8^{+}$cytotoxic T lymphocytes, which belong to the adaptive immune system. $\mathrm{T}$ helper $\mathrm{CD}^{+}$cells drive the immune response according to the pathogen (Korn and Kallies, 2017) and express both P2X7A and P2X7B receptors variants (Cheewatrakoolpong et al., 2005). As recently reviewed by Grassi (2020) and by Rivas-Yáñez et al. (2020), P2X7 receptors participate in $\mathrm{T}$ lymphocyte cell activation, migration, and differentiation. It interferes in lymph node traffic through CD62L shedding, thus being essential for $\mathrm{CD}^{+}$cell responses to injury (Yip et al., 2009; Foster et al., 2013; Grassi, 2020; Rivas-Yáñez et al., 2020). In the brain, as observed in the mouse model of experimental autoimmune encephalomyelitis (EAE), Th1 cells could induce macrophage and microglia cell activation through secretion of IFN $\gamma$ (Murphy et al., 2010). Neuroinvasion of Th1 cells could worsen cell death, both by increasing the inflammatory processes and cytokine release from active microglia cells and by inducing demyelination.

$\mathrm{CD}^{+} \mathrm{T}$ cells recognize MHC Class I molecules, acting in defense against pathogens, such as bacteria and viruses, and promote cell apoptosis by releasing cytokine enzymes such as perforin and granzymes (Janeway et al., 2001). P2X7 receptor ablation reduces differentiation of $\mathrm{T}$ cells into $\mathrm{CD} 8^{+}$ cells, inducing metabolic dysfunction and impairing $\mathrm{CD} 8^{+}$cells survival and function (Borges Da Silva et al., 2018). Moreover, long-term survival of $\mathrm{CD}^{+}$cells depends on a constant efflux of ATP maintained by P2X7 receptor activation, favoring their survival (Wanhainen et al., 2019). In view of that, P2X7 receptor inhibition could induce neuroprotection by reducing the number of $\mathrm{CD} 8^{+}$cells, which modulate synaptic plasticity and contribute to neuronal dysfunction.

Noteworthy, data regarding $\mathrm{T}$ lymphocytes in commercial available P2X7 receptor knockout (KO) mice should be carefully analyzed carefully. The GlaxoSmithKline strain failed to ablate $\mathrm{P} 2 \mathrm{X} 7$ receptor variant $\mathrm{K}(\mathrm{P} 2 \mathrm{X} 7 \mathrm{~K})$. This isoform is widely expressed in $\mathrm{T}$ lymphocytes, and these $\mathrm{KO}$ animals present increased P2X7 receptor-mediated responses in these cells (Bartlett et al., 2014).

\section{MICROGLIA: RESIDENT IMMUNE CELLS IN THE CNS PARENCHYMA}

Microglial cells are the resident immune cells within the CNS. These bone-marrow independent resident phagocytes are involved in several physiologic and pathologic processes (Huang et al., 2018). In mice, these cells are involved in synaptic pruning since postnatal brain development (Paolicelli et al., 2011) and in phagocytosing apoptotic cells during zebrafish retina development (Blume et al., 2020). Within the mouse adult brain, they are involved in immune surveillance through dynamic extending cellular processes and phagocytosis of cellular debris (Eyo et al., 2014; Cserép et al., 2020).

Besides the importance of microglial cells in normal brain physiology, there is evidence for their role during onset and progression of psychiatric and neurodegenerative diseases (Bachiller et al., 2018; Tay et al., 2018). It is known that, during neurodegenerative disease development, microglia cells shift their reactive phenotypes. Classically, microglia cells in vitro shift from protective M2 to pro-apoptotic and inflammatory M1 phenotypes (Tang and Le, 2016). These categories follow the criteria designed for M1/M2 macrophages after cytokine release stimulation by Th1/Th2 $\mathrm{CD}^{+} \mathrm{T}$ lymphocytes, respectively (Muraille et al., 2014). However, the classification of in vivo reactive states is still under debate, since unbiased gene expression profile analysis failed to identify microglial M1/M2 activation states. Thus, microglial identification through classical markers might not be optimal (Ransohoff, 2016). In this sense, recent findings suggest that microglia cells indeed show a hybrid state of activation in neurodegenerative diseases, called diseaseassociated microglia (Keren-Shaul et al., 2017). This state is proposed to delay the initial stage of disease progression, but might present deleterious effects in patient health at later stages (Song and Colonna, 2018).

In this context, mouse and rat in vitro models indicated that the P2X7 receptor activation may be involved in microglial proliferation, activation, and production of TNF- $\alpha$, and chemokines CCL2, CCL3, and CXCL2 (Suzuki et al., 2004; Bianco et al., 2006; Kataoka et al., 2009; Monif et al., 2009; Shiratori et al., 2010; Shieh et al., 2014). As previously discussed, P2X7 receptor activation enables the assembly of the NLRP3 inflammasome, and maturation and release of IL- $1 \beta$ (Bianco et al., 2005; Xu et al., 2020), triggering neuronal death (Kaur et al., 2014; Stojakovic et al., 2017) in rat and murine cell lines. This deleterious effect is supported by in vivo studies. Mice lacking NLRP3 or the IL-1 receptor (which binds IL-1 $\beta$ ) showed fewer neurodegenerative features after sepsis-induced LPS challenges (Zhao et al., 2020). Moreover, upon stimulation by LPS, striatal microglial cells turn to the activated profile and started to produce several cytokines, inducing P2X7 receptor expression upregulation. In this study, the pharmacological modulation with oxidized ATP, an P2X7 receptor antagonist, diminished the LPS effect and prevented neuroinflammation in rats (Choi et al., 2007). Controversially, murine microglia in vitro stimulated with a potent $\mathrm{P} 2 \mathrm{X} 7$ receptor agonist showed downregulation of microglial P2X7 receptor expression. This treatment induced a remarkable loss of cell viability of microglia in vivo after LPS and/or IFN- $\gamma$ stimulation (He et al., 2017), highlighting alternative $\mathrm{P} 2 \mathrm{X} 7$ receptor activity. Thus, pre-clinical evidence supports $\mathrm{P} 2 \mathrm{X} 7$ receptor participation in microglia driving neuroinflammation.

Considering the close relationship between P2X7 receptors and microglial cells, initial studies in humans proposed that P2X7 receptor ligands coupled to radiotracers can address 
the neuroinflammatory status in subjects suffering from neuroinflammatory diseases. The authors suggest that this technique would better diagnose neuroinflammation than commonly used markers do. However, a larger cohort is necessary before applying this alternative for clinical use (Hagens et al., 2020). On the other hand, another in-human pilot study with 10 Parkinson's Disease (PD) volunteers failed to identify differences in $\mathrm{P} 2 \mathrm{X} 7$ receptor radiotracer incorporation between healthy and PD subjects (Van Weehaeghe et al., 2019). In this sense, P2X7 receptor roles in triggering microglial activation could be independent from its overexpression. However, this depends on alternative $\mathrm{P} 2 \mathrm{X} 7$ receptor functioning, such as macropore formation (Van Weehaeghe et al., 2019). Although radioligand administration did not reveal any risk for healthy subjects, the efficacy of targeting P2X7 receptors as diagnostic tools for the assessment of microglial inflammation status still requires further elucidation (Van Weehaeghe et al., 2019). Thus, microglial proliferation and activation, as well as the release of pro-inflammatory factors, contribute to neuroinflammatory and neurodegenerative scenarios, augmenting the release of ATP and activating even more $\mathrm{P} 2 \mathrm{X} 7$ receptors, worsening neuroinflammation and neurodegeneration.

\section{P2X7 RECEPTOR IMMUNE MODULATION AS A TARGET FOR NEURODEGENERATIVE DISEASES}

In physiological conditions, the $\mathrm{P} 2 \mathrm{X} 7$ receptor presents low expression within CNS cells. In contrast, during stress situations in which extracellular ATP reaches high concentrations, the expression of the $\mathrm{P} 2 \mathrm{X} 7$ receptor increases. Hence, the use of pharmacological inhibition as a therapeutic strategy seems interesting from the homeostasis point of view, considering that broad $\mathrm{P} 2 \mathrm{X} 7$ receptor activation occurs mostly in inflammatory conditions, such as neurodegenerative diseases (Figure 2B). These diseases include PD, Alzheimer's disease (AD), and Multiple Sclerosis (MS). The mechanisms underlying neurodegenerative process are yet to be elucidated, although it is known that aging and neuroinflammation are key aspects (Stephenson et al., 2018). A growing number of studies indicate that not only CNS resident cells are associated with neurodegeneration. Peripheral immune cells also seem to have a key role. As previously discussed, P2X7 receptor expression is abundant in immune cells, both CNS resident and peripheral ones. Strong evidence points at beneficial effects of $\mathrm{P} 2 \mathrm{X} 7$ receptor antagonism in diseases with neuroinflammation as a culprit of neurodegeneration (Andrejew et al., 2020). For instance, $\mathrm{P} 2 \mathrm{X} 7$ receptor inhibition was recently proposed to reduce neuronal complications related to the SARS-CoV-2 infection in patients. In this scenario, the exacerbated inflammatory response induced by SARS-CoV-2 in the lungs might be mediated by $\mathrm{P} 2 \mathrm{X} 7$ receptor activation in lung and immune cells, inducing the 'cytokine storm.' This process increases BBB permeability, allowing neuroinvasion by infected peripheral immune cells and SARS-CoV-2 infection of CNS cells. In agreement with that, infiltration of such cells into the CNS may result in neuroinflammation, neurodegeneration and consequent neuropsychiatric symptoms, which are widely reported by COVID-19 patients (Ribeiro et al., 2021). Thus, it has been proposed that $\mathrm{P} 2 \mathrm{X} 7$ receptor inhibition functions as a therapeutic strategy to dampen neuroinflammation, consequently decreasing neurodegeneration, especially in $\mathrm{AD}, \mathrm{PD}$ and $\mathrm{MS}$.

\section{Alzheimer's Disease}

Alzheimer's Disease (AD) is a neurodegenerative disorder characterized by the formation of insoluble protein deposits in the CNS, composed by amyloid $\beta(\mathrm{A} \beta)$ plaques and phosphorylated Tau tangles (Polanco et al., 2018). These aggregates trigger a strong inflammatory response promoted by microglia and astrocyte activation, which are the major source of cytokines and chemokines in AD (Heneka et al., 2015), allowing the infiltration of peripheral immune cells that enhance neuroinflammation (Figure 2B; Rossi et al., 2011). Although the literature provides compelling evidence for $\mathrm{P} 2 \mathrm{X} 7$ receptorinduced effects on microglia during AD pathology, it lacks studies regarding the direct action of this receptor on peripheral immune cells. The infiltration of leukocytes is commonly observed in postmortem samples of AD subjects (Togo et al., 2002). Indeed, neutrophil CNS infiltration is associated with $\mathrm{AD}$ progression and contributes to cognitive decline in animal models of $\mathrm{AD}$ (Zenaro et al., 2015). These data reinforce the importance of studying P2X7 receptors known to modulate immune responses on peripheral immune cells and their neuroinvasion process.

P2X7 receptor roles in resident CNS immune cells (i.e., microglia) are well established, as discussed above. Pharmacological P2X7 receptor inhibition is strongly considered as a therapeutic approach in $\mathrm{AD}$, mainly because its critical role on NLRP3-induced IL-1 $\beta$ release by microglia (Biber et al., 2019). Activation of microglia in response to $\mathrm{A} \beta$ peptides requires $\mathrm{P} 2 \mathrm{X} 7$ receptor expression. This was confirmed by the lack of IL-1 $\beta$ release through inflammasome activation in cultured P2X7 receptor $\mathrm{KO}$ microglia and $\mathrm{P} 2 \mathrm{X} 7$ receptor $\mathrm{KO}$ mice (Sanz et al., 2009). Microglia samples obtained postmortem from AD subjects displayed a higher expression of $\mathrm{P} 2 \mathrm{X} 7$ receptors, when compared to healthy individuals, confirming microglia liability of P2X7 receptor activation (McLarnon et al., 2006; Martin et al., 2019).

Microglial phagocytic activity helps the CNS to perform ideal embryonic development and maintain adult homeostasis. Thus, it has come to attention that the impairment of this function is associated with neurodegenerative diseases (Galloway et al., 2019). Genome wide association studies indicated strong links between microglial genes and AD risk (Salter and Stevens, 2017). $A \beta$ plaque formation, the main hypothesis for $\mathrm{AD}$ development, focuses on the impairment of microglial activity on A $\beta$ clearance (Hardy and Higgins, 1992). In addition, phagocytosis by peripheral monocytes is also important in AD. Vascular system monocytes are attracted to the walls of $A \beta$ positive veins, promoting $A \beta$ elimination (Michaud et al., 2013). Fresh monocytes isolated from healthy individuals and $\mathrm{AD}$ patients displayed normal basal phagocytic activity. However, monocytes derived from patients with increased $A \beta$ burden had their phagocytic index activity inhibited by ATP (Gu et al., 2016). As mentioned before, P2X7 receptor expression by microglia 
and monocytes grant these cells a phagocytic ability in the absence of ATP, acting as a scavenger receptor (Gu and Wiley, 2018). Thus, high levels of ATP, as observed in exacerbated inflammation and neurodegeneration scenarios, inhibit P2X7mediated phagocytosis ( $\mathrm{Gu}$ et al., 2011). Considering that phagocytosis has a key role in $\mathrm{AD}$ pathogenesis, these data indicate that $\mathrm{P} 2 \mathrm{X} 7$ receptor scavenger activity may be important for $\mathrm{A} \beta$ clearance and preventing disease progression.

While the NLRP3 has an important participation in neuroinflammation, $\mathrm{P} 2 \mathrm{X} 7$ receptor signaling can also provide additional immune responses, as its deficiency reduces brain chemokine production. Chemokines are small proteins important for chemotaxis, recruiting peripheral immune cells. In cell culture and mouse models of $\mathrm{AD}$, brain expression of chemokines is upregulated in response to $A \beta$ aggregation. In a mouse $\mathrm{AD}$ model, $\mathrm{KO}$ for the $\mathrm{P} 2 \mathrm{X} 7$ receptor resulted in differential expression of chemokines. APPPS1xP2X7 KO mice presented significantly lower cerebral levels of chemokines CCL3, CCL4, CCL5, when compared to regular APPPS1 mice (Martin et al., 2019). Since the main function of chemokines is leukocyte recruitment, this result indicates that the lack of P2X7 receptor activation can result in decreased brain chemotaxis. CCL3 and CCL4 (MP1- $\alpha$ and MP1- $\beta$, respectively) and CCL5 chemokines are increased in brains of AD subjects (Tripathy et al., 2010), suggesting that pharmacological inhibition of the P2X7 receptor could decrease this pro-inflammatory effect during AD pathology. Further, the APPPS1xP2X7 KO mouse also displayed significantly lower infiltration of $\mathrm{CD}^{+} \mathrm{T}$ cells, both in the hippocampus and choroid plexus (Martin et al., 2019). These results confirm the specific role of the P2X7 receptor in immune responses observed during $\mathrm{AD}$, since its deficiency reduced brain chemokine release and $\mathrm{T}$ cell infiltration. In this regard, several patents of brain-penetrant P2X7 receptor antagonists were already proposed, including one for AD treatment (Bhattacharya, 2018).

\section{Parkinson's Disease}

Parkinson's disease (PD) is a neurodegenerative disease characterized by death of dopaminergic neurons from the nigrostriatal pathway and accumulation of $\alpha$-synuclein aggregates (Marino et al., 2019). An increased number of reactive microglia cells with phagocytic activity was found in postmortem brains of PD subjects (Toulorge et al., 2016), evidencing the tight relation between neuroinflammation and neurodegeneration observed in this disease (Oliveira-Giacomelli et al., 2020). In a rat model of PD, increased microglial activation is observed in injured striatum (Carmo et al., 2014) and substantia nigra, accompanied by increased $\mathrm{P} 2 \mathrm{X} 7$ receptor gene expression (Oliveira-Giacomelli et al., 2019). This effect was prevented by the use of the $\mathrm{P} 2 \mathrm{X} 7$ receptor antagonist $\mathrm{BBG}$, enabling dopaminergic neuron recovery (Oliveira-Giacomelli et al., 2019). The neuroregeneration observed in the presence of $\mathrm{P} 2 \mathrm{X} 7$ receptor antagonists is likely to be mediated by inhibition of microglial activation, since nigral dopaminergic neurons lack P2X7 receptor expression (Marcellino et al., 2010). In fact, a recent study showed that ligand-P2X7 receptor binding is increased in the striatum and substantia nigra of 6-OHDA lesioned rats and $\mathrm{P} 2 \mathrm{X} 7$ receptor expression is mainly associated with microglial cells (Crabbé et al., 2019). Corroborating this hypothesis, IL-1 $\beta$ released from microglia cells supposedly augments susceptibility of substantia nigra dopaminergic neurons to cell death in an animal model of PD (Koprich et al., 2008). Expression of the P2X7 receptor is upregulated in the brain of $\mathrm{PD}$ subjects and in 6-OHDA injured rats (Durrenberger et al., 2012; Oliveira-Giacomelli et al., 2019), which agrees with the hypothesis that microglial hyperactivation and consequent neuroinflammation contribute to dopaminergic neurodegeneration. Finally, extracellular $\alpha$-synuclein was shown to activate murine microglial cells in vitro through $\mathrm{P} 2 \mathrm{X} 7$ receptor activation and oxidative stress exacerbation (Jiang et al., 2015).

$\alpha$-synuclein protein, a key component of PD pathogenesis, binds to P2X7 receptors in microglia and stimulates its transcription (Jiang et al., 2015). Some studies found that PD subjects can have circulating $\mathrm{T}$ cells that are capable of recognizing specific epitopes of $\alpha$-synuclein, indicating that PD might result from an autoimmune response (Sulzer et al., 2017). These $\alpha$-synuclein reactive T cells may be detected years before the appearance of motor symptoms, indicating a possible target for early diagnosis of PD (Lindestam Arlehamn et al., 2020). Non-human primate PD model and PD subjects displayed chronic brain infiltration of $\mathrm{T}$ cells (Galiano-Landeira et al., 2020; Seo et al., 2020). Once in the brain, T cells recognizing $\alpha$ synuclein proteins undergo activation and initiate processes that recruit $\mathrm{P} 2 \mathrm{X} 7$ receptors.

Purinergic signaling is a critical component for the amplification of $\mathrm{T}$ cell receptor signaling (Junger, 2011). Following antigen-recognition, $\mathrm{T}$ cells release a large amount of ATP through pannexin channels, which can bind and activate P2X7 receptors. Indeed, activation of $\mathrm{T}$ cell receptors upregulated P2X7 expression in purified CD4 ${ }^{+} \mathrm{T}$ human cells (Yip et al., 2009). Blockade of $\mathrm{P} 2 \mathrm{X} 7$ receptors through different approaches, such as the use of specific antagonists, addition of apyrase to hydrolyze extracellular ATP or silencing P2X7 with siRNA, inhibited $\mathrm{T}$ cell activation (Yip et al., 2009). In PD subjects, the presence of brain infiltrated $\mathrm{CD} 8^{+} \mathrm{T}$ cells was higher compared to control subjects, and their density positively correlated with neuronal death (Galiano-Landeira et al., 2020). Considering the liability of $\mathrm{P} 2 \mathrm{X} 7$ receptor activation on $\mathrm{T}$ cell function, the $\mathrm{T}$ cell/P2X7 axis is an important matter in $\mathrm{PD}$ pathology (Figure 2C).

Chronic brain infiltration by $\mathrm{T}$ cells and other peripheral immune cells only occurs due to BBB disruption, which is commonly observed in neurodegenerative diseases (Sweeney et al., 2019). In PD, the aggregation of $\alpha$-synuclein was seen to be related to $\mathrm{BBB}$ dysfunction. Addition of $\alpha$-synuclein significantly increased the permeability of ECs in rat brain ECs co-cultured with rat brain pericytes. This increase depended, at least in part, on pericytes activation. In pericyte culture alone, $\alpha$-synuclein induced cytokine release, such as IL-1 $\beta$, IL-6, TNF$\alpha$, monocyte-attractant chemokine MCP-1 and MMP-9 (Dohgu et al., 2019). Interestingly, P2X7 receptor activation induces IL-1 $\beta$ release, which in turn promotes MMP-9 secretion and consequent BBB disruption (Yang et al., 2016). A transgenic mouse model overexpressing human $\alpha$-synuclein, revealed 
impaired BBB integrity, with vascular dysfunction, decreased levels of collagen IV and activation of pericytes, even at early stages (Elabi et al., 2021). In vivo models already showed that microglia activation in response to a neurotoxic compound induces expression upregulation of P2X7 receptors, accompanied by increased MMP-9 activity and collagen IV degradation (Rubio-Araiz et al., 2014). Importantly, $\alpha$-synuclein-induced microglial BV2 cell line activation is critically mediated by P2X7 receptors, leading to neuroblastoma $\mathrm{SH}-\mathrm{SY} 5 \mathrm{Y}$ cell apoptosis (Jiang et al., 2015). These results strongly associate P2X7 receptor activity with resident and peripheral immune cell activation during PD pathology.

\section{Multiple Sclerosis}

Several autoimmune diseases have been already associated with P2X7 receptor activation, including lupus erythematosus, rheumatoid arthritis, Sjögren's syndrome, systemic sclerosis, inflammatory bowel syndrome and Multiple Sclerosis (MS) (Cao et al., 2019). MS is an autoimmune inflammatory disorder characterized by glial cell activation, loss of oligodendrocytes, immune cell axonal damage and demyelination, mostly influenced by infiltrated peripheral immune cells (Pinheiro et al., 2016). Postmortem samples of MS subjects revealed increased expression of $\mathrm{P} 2 \mathrm{X} 7$ receptors by reactive astrocytes, especially in the frontal cortex parenchyma (Narcisse et al., 2005; Amadio et al., 2017). Nevertheless, CNS inflammation observed in MS is not only due to resident immune cell activation. Neuroinflammation observed in MS and experimental model EAE, the most common rodent model used for studying inflammation and demyelination in MS, is a consequence of a strong infiltration of peripheral immune cells.

Studies investigating the $\mathrm{P} 2 \mathrm{X} 7$ receptor in the EAE mouse model revealed conflicting results. The absence of $\mathrm{P} 2 \mathrm{X} 7$ receptor in mice seemed to decrease astroglial activation, an effect that was associated with a reduced incidence of EAE (Sharp et al., 2008). In this direction, Bernal-Chico et al. (2020) aimed to study the role of $\mathrm{P} 2 \mathrm{X} 7$ receptor $\mathrm{KO}$ in primary demyelination and remyelination, using the cuprizone model of T-cell independent myelin degeneration. Their results agree with protective features in the absence of $\mathrm{P} 2 \mathrm{X} 7$ receptor expression. In response to cuprizone, $\mathrm{P} 2 \mathrm{X} 7$ deficient mice presented diminished M1 microglia and astrogliosis, mitigated demyelination and decreased expression of pro-inflammatory genes (Bernal-Chico et al., 2020). On the other hand, reports suggest that P2X7 KO mice develop more severe clinical and pathological expression of EAE. This detrimental effect would occur through mechanisms that involve a loss of apoptotic activity in lymphocytes (Chen and Brosnan, 2006) and the enhancement of axonal damage when developing EAE (Witting et al., 2006). It is important to highlight that the diverging results can be explained, at least in part, by P2X7 receptor KO models applied in these studies. At least two mouse strains with $\mathrm{P} 2 \mathrm{X} 7$ receptor knockout are available for research purposes. Sharp and collaborators, who observed a beneficial effect of the P2X7 KO (Sharp et al., 2008) used the GlaxoSmithKline strain, in which the P2X7A receptor isoform is absent, while the $\mathrm{P} 2 \mathrm{X} 7 \mathrm{~K}$ receptor isoform is still expressed. These mice display increased P2X7 receptor-mediated responses in T-cells (Chessel et al., 2005). In contrast, works describing a prejudicial effect of $\mathrm{P} 2 \mathrm{X} 7$ receptor $\mathrm{KO}$ (Chen and Brosnan, 2006; Witting et al., 2006) used the Pfizer strain (Solle et al., 2001). This strain is deficient in both P2X7A and P2X7K isoforms of the receptor. The $\mathrm{P} 2 \mathrm{X} 7 \mathrm{~A}$ and $\mathrm{P} 2 \mathrm{X} 7 \mathrm{~K}$ isoforms seem to have unique features. For example, the P2X7K isoform is more sensitive for activation by agonists. Lower concentration of BzATP activates the P2X7K isoform, as determined in the ethidium bromide uptake assay. Further, P2X7K receptor isoform induced-ethidium uptake was independent from pannexin-1 action (Xu et al., 2012). In the P2X7A receptor isoform, the receptor C-terminal segment interacts with pannexin-1, inducing the formation of large pores in the cell membrane and leading to apoptosis (Masin et al., 2012). Therefore, it is important to establish the differences reported in the literature for each strain, for better understanding of involved mechanisms and results.

Infiltrated myelin-specific $\mathrm{T}$ cells stimulate neuroinflammation and BBB dysfunction (Figure 2D; Yamasaki et al., 2014). During MS progression, brain infiltration of leukocytes has a major contribution to the neuroinflammation observed in this pathology. MS has two hypotheses regarding the infiltration of peripheral immune cells in the CNS. The "outside-in" hypothesis indicates that $\mathrm{CD} 4^{+} \mathrm{T}$ cells are activated in the periphery and then cross the BBB. Once in the CNS, they can recognize other antigens and initiate a pro-inflammatory cascade, promoting neuroinflammation. Oppositely, the "insideout" hypothesizes that MS is originally a neurodegenerative disease eventually triggering an autoimmune reaction (Trapp and Nave, 2008). As mentioned before, P2X7 receptors exert principal functions in the signaling cascade that follows $\mathrm{T}$ cell activation (Yip et al., 2009). Despite the evidence that P2X7 receptors are widely expressed in both hematopoietic-derived and CNS resident immune cells (Collo et al., 1997; Yiangou et al., 2006; Hanley et al., 2012), knowledge is scarce regarding $\mathrm{P} 2 \mathrm{X} 7$ receptor signaling in immune cells during inflammation processes of MS pathology. It is known that the $\mathrm{KO}$ of the $\mathrm{P} 2 \mathrm{X} 7$ gene in mice leads to a more severe clinical and pathological EAE (Chen and Brosnan, 2006). Circulating monocytes of healthy subjects express the $\mathrm{P} 2 \mathrm{X} 7$ receptor, and this expression was observed to be downregulated in monocytes obtained from stable and acute MS subjects. The same result was identified in the rat EAE model. On the other hand, infiltrated monocytes expressing P2X7 receptors were also upregulated in the frontal cortex blood vessels of secondary progressive MS subjects. In the same area of the frontal cortex, increased expression of the leukocyte-attractant chemokine MCP-1, was co-localized with P2X7 receptor expression (Amadio et al., 2017). MCP-1 is also co-localized with astrocytes in MS-derived lesions, as shown in human postmortem tissue (Simpson et al., 1998). Further, in vitro assays revealed that BzATP through P2X7 receptor activation enhanced MCP-1 expression in rat astrocytes (Panenka et al., 2001). Amadio et al. (2017) developed the hypothesis that during initial stages of MS, CNS homeostasis loss leads to an increase in extracellular ATP, activating P2X7 receptors, which are upregulated in their expression levels in astrocytes. Increased release of MCP-1 promotes peripheral monocyte chemotaxis, which in turn downregulates P2X7 
receptor expression to ensure their survival and CNS invasion. The result is augmented neuroinflammation, resulting in neurodegeneration.

The MS EAE mouse model is also linked to increased BBB permeability (Alvarez et al., 2011). P2X7 receptor expression was found in pericytes of cerebral microvessels in both EAE and wild-type (WT) rats. In the EAE model, ATP-dependent $\mathrm{P} 2 \mathrm{X} 7$ receptor activation induced oligodendrocyte excitotoxicity and promoted neuronal damage similar to that observed in MS, including demyelination and axonal impairment (Matute et al., 2007). Upregulation of P2X7 receptor expression located in astroglia of these animals can be observed at early stages, before symptoms, such as tail paralysis and loss of reflexes, have developed (Grygorowicz et al., 2010). EAE rats develop neurological deficits, whose severity was reduced when BBG had been administered. Throughout the development of the disease, the animals showed increased P2X7 receptor expression, followed by decreased pericyte immunostaining and claudin5 levels (Grygorowicz et al., 2018). Treatment with the P2X7 receptor antagonist BBG restored pericyte and claudin-5 levels (Grygorowicz et al., 2018). As pericytes are responsible for proper regulation of $\mathrm{BBB}$ permeability, their deficit leads to a reduction in tight junction proteins (Bell et al., 2010) and to an increase in BBB permeability (Nisancioglu et al., 2010). Thus, these results indicate the participation of the $\mathrm{P} 2 \mathrm{X} 7$ receptor as a mediator of interactions between ECs and pericytes in MS. Evidence suggests direct and indirect participation of this receptor in the processes that cause $\mathrm{BBB}$ rupture and permeabilization in some neurological disorders. However, exact mechanisms need to be better elucidated for the understanding of the molecular biology of the disorders and especially for possible therapeutic approaches.

Due to the autoimmune nature of MS and its effects on $\mathrm{BBB}$ integrity, PVMs are a promising target in MS. In fact, PVMs seem to contribute to MS progression and pathogenesis. Increased numbers of PVMs were detected in MS brain subjects (Zhang et al., 2011) and in the EAE animal model, as well as CD163-associated PVMs expression and leukocyte infiltration before symptoms' onset (Polfliet et al., 2002). PVM depletion induced by clodronate liposomes protected against symptoms' appearance (Polfliet et al., 2002). Additionally, spinal PVMs presented upregulation of CD45, CD106, CCL2, and CCL3 protein expression in the EAE model (Hofmann et al., 2002), indicating that chemokines may recruit monocytes and contribute with the demyelinating pathogenesis. The leukocyte chemoattractant CCL3 chemokine is also released by ECs during inflammation (Chui and Dorovini-Zis, 2010). Importantly, in an $\mathrm{AD}$ neuroinflammation model, the $\mathrm{KO}$ of the $\mathrm{P} 2 \mathrm{X} 7$ receptor significantly decreased the CCL3 chemokine release (Martin et al., 2019), indicating that the activation of this receptor may contribute to this inflammatory aspect of MS.

\section{CONCLUSION}

The neurodegenerative process is often accompanied by an exacerbated neuroinflammatory response, with increased ATP release, microglia proliferation, as well as activation and release of proinflammatory factors. These processes are known to be mediated by P2X7 receptors, through assembly of NLRP3 inflammasome and maturation/secretion of IL- $1 \beta$, TNF- $\alpha$ and other cytokines and chemokines. In turn, IL-1 $\beta$ triggers production of MMP-9 by immune and BBB cells, degrading tight junction proteins and resulting in $\mathrm{BBB}$ disruption.

The permeable $\mathrm{BBB}$ allows the infiltration of peripheral immune cells into the CNS. The availability of these cells involves P2X7 receptor activation, since it modulates differentiation, release, activation and function of monocytes/macrophages and $\mathrm{T}$ cells. Moreover, although promising, there are no available data regarding $\mathrm{P} 2 \mathrm{X} 7$ receptor modulation of PVMs activity, since it regulates peripheral immune cells trafficking through the BBB. Once in the brain, these cells can also induce microglial responses. Basically, P2X7 receptor involvement in these processes occurs as a positive feedback loop, releasing factors that amplify its activation, resulting in exacerbation of the inflammation due to microglial activation, immune cells recruitment, and autoimmune responses with consequent worsening of neurodegeneration. In neurodegenerative disorders, the initial inflammatory process is crucial for disease progression and is highly upregulated by $\mathrm{P} 2 \mathrm{X} 7$ receptor activation. In $\mathrm{AD}, \mathrm{PD}$, and $\mathrm{MS}$, microglial activation and leukocyte infiltration are immune features observed in the brain. This proinflammatory state occurs in early disease stages and in parallel to disease progression, as a key factor leading to demyelination and neuronal death. Thus, P2X7 receptor antagonism could be a promising target for neurodegenerative diseases associated with inflammation and immune responses in the brain.

\section{AUTHOR CONTRIBUTIONS}

ÁO-G: sections "Neuroinvasion of Peripheral Immune Cells: Blood-Brain-Barrier Permeability" and "P2X7 Receptor Immune Modulation as a Target for Neurodegenerative Diseases" writing and Figure 1. LP: section "P2X7 Receptor Immune Modulation as a Target for Neurodegenerative Diseases" writing and manuscript organization. RA: sections "Peripheral Immune cells" and "Conclusion" writing and Figure 2. NT: section "Peripheral Immune Cells" writing and Figure 2. JS: sections "Conclusion" and "Microglia" writing and Figure 2. US: manuscript conception and critical article review for important intellectual content. HU: manuscript conception and writing and critical article review for intellectual content. All authors contributed to the article and approved the submitted version.

\section{FUNDING}

HU acknowledges grant support from the São Paulo Research Foundation (FAPESP, Project Nos. 2018/073664 and 2018/08426-0). HU acknowledges the National Council for Scientific and Technological Development for fellowship support (CNPq, Project No. 306392/2017-8). 
ÁO-G is grateful for postdoctoral fellowships granted by FAPESP (Project No. 2019/26852-0). LP is grateful for a CNPq DTI-A fellowship (CNPq 380405/2020-2). NT and RA are grateful for doctoral fellowships from FAPESP (Project Nos. 2020/107256 and 2019/24553-5). JS is grateful for a master student

\section{REFERENCES}

Adinolfi, E., Cirillo, M., Woltersdorf, R., Falzoni, S., Chiozzi, P., Pellegatti, P., et al. (2010). Trophic activity of a naturally occurring truncated isoform of the P2X7 receptor. FASEB J. 24, 3393-3404. doi: 10.1096/fj.09-153601

Agrawal, S., Anderson, P., Durbeej, M., Van Rooijen, N., Ivars, F., Opdenakker, G., et al. (2006). Dystroglycan is selectively cleaved at the parenchymal basement membrane at sites of leukocyte extravasation in experimental autoimmune encephalomyelitis. J. Exp. Med. 203, 1007-1016. doi: 10.1084/jem.2005 1342

Alberto, A. V. P., Faria, R. X., Couto, C. G. C., Ferreira, L. G. B., Souza, C. A. M., Teixeira, P. C. N., et al. (2013). Is pannexin the pore associated with the P2X7 receptor? Naunyn. Schmiedebergs. Arch. Pharmacol. 386, 775-787. doi: 10.1007/ s00210-013-0868-x

Alvarez, J. I., Dodelet-Devillers, A., Kebir, H., Ifergan, I., Fabre, P. J., Terouz, S., et al. (2011). The hedgehog pathway promotes blood-brain barrier integrity and CNS immune quiescence. Science 334, 1727-1731. doi: 10.1126/science. 1206936

Amadio, S., Parisi, C., Piras, E., Fabbrizio, P., Apolloni, S., Montilli, C., et al. (2017). Modulation of P2X7 receptor during inflammation in multiple sclerosis. Front. Immunol. 8:1529. doi: 10.3389/fimmu.2017.01529

Anderson, J. M., and Van Itallie, C. M. (1995). Tight junctions and the molecular basis for regulation of paracellular permeability. Am. J. Physiol. 269, G467G475. doi: 10.1152/ajpgi.1995.269.4.G467

Andrejew, R., Oliveira-Giacomelli, Á, Ribeiro, D. E., Glaser, T., Arnaud-Sampaio, V. F., Lameu, C., et al. (2020). The P2X7 receptor: central hub of brain diseases. Front. Mol. Neurosci. 13:124. doi: 10.3389/fnmol.2020.00124

Bachiller, S., Jiménez-Ferrer, I., Paulus, A., Yang, Y., Swanberg, M., Deierborg, T., et al. (2018). Microglia in neurological diseases: a road map to brain-disease dependent-inflammatory response. Front. Cell. Neurosci. 12:488. doi: 10.3389/ fncel.2018.00488

Baeten, K. M., and Akassoglou, K. (2011). Extracellular matrix and matrix receptors in blood-brain barrier formation and stroke. Dev. Neurobiol. 71, 1018-1039. doi: 10.1002/dneu.20954

Bai, Y., Zhu, X., Chao, J., Zhang, Y., Qian, C., Li, P., et al. (2015). Pericytes contribute to the disruption of the cerebral endothelial barrier via increasing VEGF expression: implications for stroke. PLoS One 10:e0124362. doi: 10.1371/ journal.pone. 0124362

Bartlett, R., Stokes, L., and Sluyter, R. (2014). The P2X7 receptor channel: recent developments and the use of P2X7 antagonists in models of disease. Pharmacol. Rev. 66, 638-675. doi: 10.1124/pr.113.008003

Bechmann, I., Galea, I., and Perry, V. H. (2007). What is the blood-brain barrier (not)? Trends Immunol. 28, 5-11. doi: 10.1016/j.it.2006.11.007

Bechmann, I., Kwidzinski, E., Kovac, A. D., Simbürger, E., Horvath, T., Gimsa, U., et al. (2001). Turnover of rat brain perivascular cells. Exp. Neurol. 168, 242-249. doi: 10.1006/exnr.2000.7618

Bell, R. D., Winkler, E. A., Sagare, A. P., Singh, I., Larue, B., and Deane, R. (2010). Article pericytes control key neurovascular functions and neuronal phenotype in the adult brain and during brain aging. Neuron 68, 409-427. doi: 10.1016/j. neuron.2010.09.043

Bernal-Chico, A., Manterola, A., Cipriani, R., Katona, I., Matute, C., and Mato, S. (2020). P2X7 receptors control demyelination and inflammation in the cuprizone model. Brain Behav. Immun. Health 4:100062. doi: 10.1016/j.bbih. 2020.100062

Bhattacharya, A. (2018). Recent advances in CNS P2X7 physiology and pharmacology: focus on neuropsychiatric disorders. Front. Pharmacol. 9:30. doi: 10.3389/fphar.2018.00030

Bianco, F., Ceruti, S., Colombo, A., Fumagalli, M., Ferrari, D., Pizzirani, C., et al. (2006). A role for P2X7 in microglial proliferation. J. Neurochem. 99, 745-758. doi: $10.1111 /$ j.1471-4159.2006.04101.x fellowship granted by the Coordination of Superior Level Staff Improvement (CAPES, Project No. 88887.517645/2020-00). We acknowledge support from the German Research Foundation (DFG) and Universität Leipzig within the program of Open Access Publishing.

Bianco, F., Pravettoni, E., Colombo, A., Schenk, U., Möller, T., Matteoli, M., et al. (2005). Astrocyte-Derived ATP induces vesicle shedding and IL-1 $\beta$ release from Microglia. J. Immunol. 174, 7268-7277. doi: 10.4049/jimmunol.174.11.7268

Biber, K., Bhattacharya, A., Campbell, B. M., Piro, J. R., Rohe, M., Staal, R. G. W., et al. (2019). Microglial drug targets in AD: opportunities and challenges in drug discovery and development. Front Pharmacol 10:840. doi: 10.3389/fphar.2019. 00840

Blume, Z. I., Lambert, J. M., Lovel, A. G., and Mitchell, D. M. (2020). Microglia in the developing retina couple phagocytosis with the progression of apoptosis via P2RY12 signaling. Dev. Dyn. 249, 723-740. doi: 10.1002/dvdy.163

Bonkowski, D., Katyshev, V., Balabanov, R. D., Borisov, A., and Dore-Duffy, P. (2011). The CNS microvascular pericyte: pericyte-astrocyte crosstalk in the regulation of tissue survival. Fluids Barriers CNS 8:8. doi: 10.1186/2045-81188-8

Borges Da Silva, H., Beura, L. K., Wang, H., Hanse, E. A., Gore, R., Scott, M. C., et al. (2018). The purinergic receptor P2RX7 directs metabolic fitness of long-lived memory CD8 ${ }^{+}$T cells. Nature 559, 264-268. doi: 10.1038/s41586-018-0282-0

Burnstock, G. (2018). Purine and purinergic receptors. Brain Neurosci. Adv. 2, 1-10. doi: $10.1177 / 2398212818817494$

Burnstock, G., and Kennedy, C. (2011). "P2X receptors in health and disease," in Advances in Pharmacology, eds K. A. Jacobson, and J. Linden (Cambridge, MA: Academic Press Inc.), 333-372. doi: 10.1016/B978-0-12-385526-8.00011-4

Cao, F., Hu, L.-Q., Yao, S.-R., Hu, Y., Wang, D.-G., Fan, Y.-G., et al. (2019). P2X7 receptor: a potential therapeutic target for autoimmune diseases. Autoimmun. Rev. 18, 767-777. doi: 10.1016/j.autrev.2019.06.009

Carmo, M. R. S., Menezes, A. P. F., Nunes, A. C. L., Pliássova, A., Rolo, A. P., Palmeira, C. M., et al. (2014). The P2X7 receptor antagonist Brilliant Blue $G$ attenuates contralateral rotations in a rat model of Parkinsonism through a combined control of synaptotoxicity, neurotoxicity and gliosis. Neuropharmacology 81, 142-152. doi: 10.1016/j.neuropharm.2014. 01.045

Cheewatrakoolpong, B., Gilchrest, H., Anthes, J. C., and Greenfeder, S. (2005). Identification and characterization of splice variants of the human P2X7 ATP channel. Biochem. Biophys. Res. Commun. 332, 17-27. doi: 10.1016/j.bbrc.2005. 04.087

Chen, L., and Brosnan, C. (2006). Exacerbation of experimental autoimmune encephalomyelitis in P2X7R -/- Mice: evidence for loss of apoptotic activity in lymphocytes. J. Immunol. 176, 3115-3126. doi: 10.4049/jimmunol. 176.5.3115

Chessel, I. P., Hatcher, J. P., Bountra, C., Michel, A. D., Hughes, J. P., Green, P., et al. (2005). Disruption of the P2X7 purinoceptor gene abolishes chronic inflammatory and neuropathic pain. Pain 114, 386-396. doi: 10.1016/j.pain. 2005.01.002

Cho, J.-H., Choi, I.-S., and Jang, I.-S. (2010). P2X7 receptors enhance glutamate release in hippocampal hilar neurons. Neuroreport 21, 865-870. doi: 10.1097/ WNR.0b013e32833d9142

Choi, H. B., Ryu, J. K., Kim, S. U., and McLarnon, J. G. (2007). Modulation of the purinergic P2X7 receptor attenuates lipopolysaccharide-mediated microglial activation and neuronal damage in inflamed brain. J. Neurosci. 27, 4957-4968. doi: 10.1523/JNEUROSCI.5417-06.2007

Chui, R., and Dorovini-Zis, K. (2010). Regulation of CCL2 and CCL3 expression in human brain endothelial cells by cytokines and lipopolysaccharide. J. Neuroinflammation 7:1. doi: 10.1186/1742-2094-7-1

Collo, G., Neidhart, S., Kawashima, E., Kosco-Vilbois, M., North, R. A., and Buell, G. (1997). Tissue distribution of the P2X7 receptor. Neuropharmacology 36, 1277-1283. doi: 10.1016/s0028-3908(97)00140-8

Crabbé, M., Van Der Perren, A., Bollaerts, I., Kounelis, S., Baekelandt, V., Bormans, G., et al. (2019). Increased P2X7 receptor binding is associated with neuroinflammation in acute but not chronic rodent models for Parkinson's disease. Front. Neurosci. 13:799. doi: 10.3389/fnins.2019.00799 
Cserép, C., Pósfai, B., Lénárt, N., and Dénes, Á (2020). Microglia monitor and protect neuronal function via specialized somatic purinergic junctions. Science 367, 528-537. doi: 10.1126/science.aax6752

Daneman, R., Zhou, L., Kebede, A. A., and Barres, B. A. (2010). Pericytes are required for blood-brain barrier integrity during embryogenesis. Nature 468, 562-566. doi: 10.1038/nature09513

De Torre-Minguela, C., Barberà-Cremades, M., Gómez, A. I., Martín-Sánchez, F., and Pelegrín, P. (2016). Macrophage activation and polarization modify P2X7 receptor secretome influencing the inflammatory process. Sci. Rep. 6:22586. doi: $10.1038 /$ srep22586

Di Virgilio, F. (2007). Purinergic signalling in the immune system. A brief update. Purinergic Signal. 3, 1-3. doi: 10.1007/s11302-006-9048-5

Di Virgilio, F., Dal Ben, D., Sarti, A. C., Giuliani, A. L., and Falzoni, S. (2017). The P2X7 receptor in infection and inflammation. Immunity 47, 15-31. doi: 10.1016/j.immuni.2017.06.020

Di Virgilio, F., Schmalzing, G., and Markwardt, F. (2018). The elusive P2X7 macropore. Trends Cell Biol. 28, 392-404. doi: 10.1016/j.tcb.2018.01.005

Dohgu, S., Takata, F., Matsumoto, J., Kimura, I., Yamauchi, A., and Kataoka, Y. (2019). Monomeric $\alpha$-synuclein induces blood-brain barrier dysfunction through activated brain pericytes releasing inflammatory mediators in vitro. Microvasc. Res. 124, 61-66. doi: 10.1016/j.mvr.2019.03.005

Durrenberger, P. F., Grünblatt, E., Fernando, F. S., Monoranu, C. M., Evans, J., Riederer, P., et al. (2012). Inflammatory pathways in Parkinson's disease; a BNE microarray study. Parkinsons Dis. 2012:214714. doi: 10.1155/ $2012 / 214714$

Elabi, O., Gaceb, A., Carlsson, R., Padel, T., Soylu-Kucharz, R., Cortijo, I., et al. (2021). Human $\alpha$-synuclein overexpression in a mouse model of Parkinson's disease leads to vascular pathology, blood brain barrier leakage and pericyte activation. Sci. Rep. 11:1120. doi: 10.1038/s41598-020-80889-8

Engelhardt, B., and Liebner, S. (2014). Novel insights into the development and maintenance of the blood - brain barrier. Cell Tissue Res. 355, 687-699. doi: 10.1007/s00441-014-1811-2

Eyo, U. B., Peng, J., Swiatkowski, P., Mukherjee, A., Bispo, A., and Wu, L. J. (2014). Neuronal hyperactivity recruits microglial processes via neuronal NMDA receptors and microglial P2Y12 receptors after status epilepticus. J. Neurosci. 34, 10528-10540. doi: 10.1523/JNEUROSCI.0416-14.2014

Filipowicz, A. R., McGary, C. M., Holder, G. E., Lindgren, A. A., Johnson, E. M., Sugimoto, C., et al. (2016). Proliferation of perivascular macrophages contributes to the development of encephalitic lesions in HIV-Infected humans and in SIV-infected macaques. Sci. Rep. 6:32900. doi: 10.1038/srep32900

Foster, J. G., Carter, E., Kilty, I., MacKenzie, A. B., and Ward, S. G. (2013). Mitochondrial superoxide generation enhances P2X7R-Mediated loss of cell surface CD62L on naive human $\mathrm{CD}^{+} \mathrm{T}$ lymphocytes. J. Immunol. 190, 1551-1559. doi: 10.4049/jimmunol.1201510

Franco, M., Roswall, P., Cortez, E., Hanahan, D., and Pietras, K. (2011). Pericytes promote endothelial cell survival through induction of autocrine VEGFAsignaling and Bcl-w expression. Blood 118, 2906-2917. doi: 10.1182/blood2011-01-331694

Galiano-Landeira, J., Torra, A., Vila, M., and Bové, J. (2020). CD8 T cell nigral infiltration precedes synucleinopathy in early stages of Parkinson's disease. Brain 143, 3717-3733. doi: 10.1093/brain/awaa269

Galloway, D. A., Philips, A. E. M., Owen, D. R. J., and Moore, C. S. (2019). Phagocytosis in the brain: homeostasis and disease. Front Immunol 10:790. doi: 10.3389/fimmu.2019.00790

Gasche, Y., Copin, J. C., Sugawara, T., Fujimura, M., and Chan, P. H. (2001). Matrix metalloproteinase inhibition prevents oxidative stress-associated blood-brain barrier disruption after transient focal cerebral ischemia. J. Cereb. Blood Flow Metab. 21, 1393-1400. doi: 10.1097/00004647-20011200000003

Giuliani, A. L., Sarti, A. C., Falzoni, S., and Di Virgilio, F. (2017). The P2X7 Receptor-Interleukin-1 Liaison. Front Pharmacol 8:123. doi: 10.3389/fphar. 2017.00123

Goldmann, T., Wieghofer, P., Jordão, M. J. C., Prutek, F., Hagemeyer, N., Frenzel, K., et al. (2016). Origin, fate and dynamics of macrophages at central nervous system interfaces. Nat. Immunol. 17, 797-805. doi: 10.1038/ni.3423

Gottschall, P. E. (2016). Regulation of matrix metalloproteinase expression in astrocytes, microglia and neurons. Neuroimmunomodulation 3, 69-75. doi: 10. $1159 / 000097229$
Grassi, F. (2020). The P2X7 receptor as regulator of T cell development and function. Front. Immunol. 11:1179. doi: 10.3389/fimmu.2020.01179

Greenwood, J., Etienne-Manneville, S., Adamson, P., and Couraud, P. O. (2002). Lymphocyte migration into the central nervous system: implication of ICAM1 signalling at the blood-brain barrier. Vascul. Pharmacol. 38, 315-322. doi: 10.1016/S1537-1891(02)00199-4

Grygorowicz, T., Dąbrowska-Bouta, B., and Strużyńska, L. (2018). Administration of an antagonist of $\mathrm{P} 2 \mathrm{X} 7$ receptor to EAE rats prevents a decrease of expression of claudin-5 in cerebral capillaries. Purinergic Signal. 14, 385-393. doi: 10.1007/ s11302-018-9620-9

Grygorowicz, T., Struzyńska, L., Sulkowski, G., Chalimoniuk, M., and Sulejczak, D. (2010). Temporal expression of P2X7 purinergic receptor during the course of experimental autoimmune encephalomyelitis. Neurochem. Int. 57, 823-829. doi: 10.1016/j.neuint.2010.08.021

Gu, B., Bendall, L. J., and Wiley, J. S. (1998). Adenosine triphosphate-induced shedding of CD23 and L-selectin (CD62L) from lymphocytes is mediated by the same receptor but different metalloproteases. Blood 92, 946-951. doi: 10.1182/blood.v92.3.946

Gu, B. J., Huang, X., Ou, A., Rembach, A., Fowler, C., Avula, P. K., et al. (2016). Innate phagocytosis by peripheral blood monocytes is altered in Alzheimer's disease. Acta Neuropathol 132, 377-389. doi: 10.1007/s00401-016-1596-3

Gu, B. J., Saunders, B. M., Jursik, C., and Wiley, J. S. (2010). The P2X7-nonmuscle myosin membrane complex regulates phagocytosis of nonopsonized particles and bacteria by a pathway attenuated by extracellular ATP. Blood 115, 16211631. doi: 10.1182/blood-2009-11-251744

Gu, B. J., Saunders, B. M., Petrou, S., and Wiley, J. S. (2011). P2X 7 is a scavenger receptor for apoptotic cells in the absence of its ligand, extracellular ATP. J. Immunol. 187, 2365-2375. doi: 10.4049/jimmunol.1101178

$\mathrm{Gu}$, B. J., and Wiley, J. S. (2006). Rapid ATP-induced release of matrix metalloproteinase 9 is mediated by the P2X7 receptor. Blood 107, 4946-4953. doi: 10.1182/blood-2005-07-2994

$\mathrm{Gu}$, B. J., and Wiley, J. S. (2018). P2X7 as a scavenger receptor for innate phagocytosis in the brain. Br. J. Pharmacol. 175, 4195-4208. doi: 10.1111/bph. 14470

Gudipaty, L., Humphreys, B. D., Buell, G., and Dubyak, G. R. (2001). Regulation of P2X7 nucleotide receptor function in human monocytes by extracellular ions and receptor density. Am. J. Physiol. Cell Physiol. 280, C943-C953. doi: 10.1152/ajpcell.2001.280.4.c943

Hagens, M. H. J., Golla, S. S. V., Janssen, B., Vugts, D. J., Beaino, W., Windhorst, A. D., et al. (2020). The P2X7 receptor tracer [11C]SMW139 as an in vivo marker of neuroinflammation in multiple sclerosis: a first-in man study. Eur. J. Nucl. Med. Mol. Imaging 47, 379-389. doi: 10.1007/s00259-019-04550-x

Hanley, P. J., Kronlage, M., Kirschning, C., del Rey, A., Di Virgilio, F., Leipziger, J., et al. (2012). Transient P2X7 receptor activation triggers macrophage death independent of Toll-like receptors 2 and 4, caspase-1, and pannexin-1 proteins. J Biol. Chem. 287, 10650-10663. doi: 10.1074/jbc.M111.332676

Hardy, J. A., and Higgins, G. A. (1992). Alzheimer's disease: the amyloid cascade hypothesis. Science 256, 184-185. doi: 10.1126/science. 1566067

Harkness, K. A. C., Adamson, P., Sussman, J. D., Davies-Jones, G. A. B., Greenwood, J., and Woodroofe, M. N. (2000). Dexamethasone regulation of matrix metalloproteinase expression in CNS vascular endothelium. Brain 123, 698-709. doi: 10.1093/brain/123.4.698

He, W. T., Wan, H., Hu, L., Chen, P., Wang, X., Huang, Z., et al. (2015). Gasdermin $\mathrm{D}$ is an executor of pyroptosis and required for interleukin-1 $\beta$ secretion. Cell Res. 25, 1285-1298. doi: 10.1038/cr.2015.139

He, Y., Taylor, N., Fourgeaud, L., and Bhattacharya, A. (2017). The role of microglial P2X7: modulation of cell death and cytokine release. J. Neuroinflammation 14:135. doi: 10.1186/s12974-017-0904-8

Heneka, M. T., Carson, M. J., El Khoury, J., Landreth, G. E., Brosseron, F., Feinstein, D. L., et al. (2015). Neuroinflammation in Alzheimer's disease. Lancet Neurol. 14, 388-405. doi: 10.1016/S1474-4422(15)70016-5

Hofmann, N., Lachnit, N., Streppel, M., Witter, B., Neiss, W., Guntinas-Lichius, O., et al. (2002). Increased expression of ICAM-1, VCAM-1, MCP-1, and MIP- $1 \alpha$ by spinal perivascular macrophages during experimental allergic encephalomyelitis in rats. BMC Immunol. 3:11. doi: 10.1186/1471-2172-3-11

Huang, Y., Xu, Z., Xiong, S., Sun, F., Qin, G., Hu, G., et al. (2018). Repopulated microglia are solely derived from the proliferation of residual microglia after acute depletion. Nat. Neurosci. 21, 530-540. doi: 10.1038/s41593-018-0090-8 
Hurtado-Alvarado, G., Cabañas-Morales, A. M., and Gómez-Gónzalez, B. (2014). Pericytes: brain-immune interface modulators. Front. Integr. Neurosci. 7:80. doi: $10.3389 /$ fnint.2013.00080

Iadecola, C. (2017). Review the neurovascular unit coming of age: a journey through neurovascular coupling in health and disease. Neuron 96, 17-42. doi: 10.1016/j.neuron.2017.07.030

Jamieson, G. P., Snook, M. B., Thurlow, P. J., and Wiley, J. S. (1996). Extracellular ATP causes of loss of L-selectin from human lymphocytes via occupancy of P2Z purinoceptors. J. Cell. Physiol. 166, 637-642. doi: 10.1002/(sici)10974652(199603)166:3<637::aid-jcp19>3.0.co;2-3

Janeway, C. A., Travers, P., Walport, M., and Shlomchik, M. J. (2001). “T CellMediated Immunity," in Immunobiology: The Immune System in Health and Disease, (New York, NY: Garland Science). Available online at: https://www. ncbi.nlm.nih.gov/books/NBK27101/ (accessed January 28, 2021).

Jiang, T., Hoekstra, J., Heng, X., Kang, W., Ding, J., Liu, J., et al. (2015). P2X7 receptor is critical in $\alpha$-synuclein-mediated microglial NADPH oxidase activation. Neurobiol. Aging 36, 2304-2318. doi: 10.1016/j.neurobiolaging.2015. 03.015

Junger, W. G. (2011). Immune cell regulation by autocrine purinergic signalling. Nat. Rev. Immunol. 11, 201-212. doi: 10.1038/nri2938

Kataoka, A., Tozaki-Saitoh, H., Koga, Y., Tsuda, M., and Inoue, K. (2009). Activation of P2X7 receptors induces CCL3 production in microglial cells through transcription factor NFAT. J. Neurochem. 108, 115-125. doi: 10.1111/j. 1471-4159.2008.05744.x

Katsu, M., Niizuma, K., Yoshioka, H., Okami, N., Sakata, H., and Chan, P. H. (2010). Hemoglobin-induced oxidative stress contributes to matrix metalloproteinase activation and blood - brain barrier dysfunction in vivo. J. Cereb. Blood Flow Metab. 30, 1939-1950. doi: 10.1038/jcbfm.2010.45

Kaur, C., Sivakumar, V., Zou, Z., and Ling, E. A. (2014). Microglia-derived proinflammatory cytokines tumor necrosis factor-alpha and interleukin-1beta induce Purkinje neuronal apoptosis via their receptors in hypoxic neonatal rat brain. Brain Struct. Funct. 219, 151-170. doi: 10.1007/s00429-012-0491-5

Keren-Shaul, H., Spinrad, A., Weiner, A., Matcovitch-Natan, O., Dvir-Szternfeld, R., Ulland, T. K., et al. (2017). A Unique microglia type associated with restricting development of Alzheimer's disease. Cell 169, 1276-1290. doi: 10. 1016/j.cell.2017.05.018

Kim, J. H., Kim, J. H., Yu, Y. S., Kim, D. H., and Kim, K. W. (2009). Recruitment of pericytes and astrocytes is closely related to the formation of tight junction in developing retinal vessels. J. Neurosci. Res. 87, 653-659. doi: 10.1002/jnr.21884

Koizumi, T., Kerkhofs, D., Mizuno, T., Steinbusch, H. W. M., and Foulquier, S. (2019). Vessel-Associated immune cells in cerebrovascular diseases: from perivascular macrophages to vessel-associated microglia. Front. Neurosci. 13:1291. doi: 10.3389/fnins.2019.01291

Koprich, J. B., Reske-Nielsen, C., Mithal, P., and Isacson, O. (2008). Neuroinflammation mediated by IL- $1 \beta$ increases susceptibility of dopamine neurons to degeneration in an animal model of Parkinson's disease. J. Neuroinflammation 5:8. doi: 10.1186/1742-2094-5-8

Korn, T., and Kallies, A. (2017). T cell responses in the central nervous system. Nat. Rev. Immunol. 17, 179-194. doi: 10.1038/nri.2016.144

Lee, J. K., Jin, H. K., Endo, S., Schuchman, E. H., Carter, J. E., and Bae, J.-S. (2010). Intracerebral transplantation of bone marrow-derived mesenchymal stem cells reduces amyloid-beta deposition and rescues memory deficits in Alzheimer's disease mice by modulation of immune responses. Stem Cells 28, 329-343. doi: $10.1002 /$ stem. 277

Lieberman, J., Wu, H., and Kagan, J. C. (2019). Gasdermin D activity in inflammation and host defense. Sci. Immunol. 4, 1-9. doi: 10.1126/sciimmunol. aav1447

Lindestam Arlehamn, C. S., Dhanwani, R., Pham, J., Kuan, R., Frazier, A., Rezende Dutra, J., et al. (2020). $\alpha$-Synuclein-specific T cell reactivity is associated with preclinical and early Parkinson's disease. Nat. Commun. 11:1875. doi: 10.1038/ s41467-020-15626-w

Liu, K. J., and Rosenberg, G. A. (2005). Matrix metalloproteinases and free radicals in cerebral ischemia. Free Radic. Biol. Med. 39, 71-80. doi: 10.1016/j. freeradbiomed.2005.03.033

Liu, X., Zhang, Z., Ruan, J., Pan, Y., Magupalli, V. G., Wu, H., et al. (2016). Inflammasome-activated gasdermin $\mathrm{D}$ causes pyroptosis by forming membrane pores. Nature 535, 153-158. doi: 10.1038/nature18629
Marcellino, D., Suárez-Boomgaard, D., Sánchez-Reina, M. D., Aguirre, J. A., Yoshitake, T., Yoshitake, S., et al. (2010). On the role of P2X7 receptors in dopamine nerve cell degeneration in a rat model of Parkinson's disease: studies with the P2X7 receptor antagonist A-438079. J. Neural Transm. 117, 681-687. doi: 10.1007/s00702-010-0400-0

Marino, B. L. B., de Souza, L. R., Sousa, K. P. A., Ferreira, J. V., Padilha, E. C., da Silva, C. H. T. P., et al. (2019). Parkinson's disease: a review from pathophysiology to treatment. Mini Rev. Med. Chem. 20, 754-767. doi: 10.2174/ 1389557519666191104110908

Martin, E., Amar, M., Dalle, C., Youssef, I., Boucher, C., Le Duigou, C., et al. (2019). New role of P2X7 receptor in an Alzheimer's disease mouse model. Mol. Psychiatry 24, 108-125. doi: 10.1038/s41380-018-0108-3

Masin, M., Young, C., Lim, K., Barnes, S. J., Xu, X. J., Marschall, V., et al. (2012). Expression, assembly and function of novel C-terminal truncated variants of the mouse P2X7 receptor: re-evaluation of P2X7 knockouts. Br. J. Pharmacol. 165, 978-993. doi: 10.1111/j.1476-5381.2011.01624.x

Matute, C., Torre, I., Perez-Cerda, F., Perez-Samartin, A., Alberdi, E., Etxebarria, E., et al. (2007). P2X7 receptor blockade prevents ATP excitotoxicity in oligodendrocytes and ameliorates experimental autoimmune encephalomyelitis. J. Neurosci. 27, 9525-9533. doi: 10.1523/JNEUROSCI.057907.2007

McLarnon, J. G., Ryu, J. K., Walker, D. G., and Choi, H. B. (2006). Upregulated expression of purinergic P2X(7) receptor in Alzheimer disease and amyloidbeta peptide-treated microglia and in peptide-injected rat hippocampus. J. Neuropathol. Exp. Neurol. 65, 1090-1097. doi: 10.1097/01.jnen.0000240470. 97295.d3

Melani, A., Turchi, D., Vannucchi, M. G., Cipriani, S., Gianfriddo, M., and Pedata, F. (2005). ATP extracellular concentrations are increased in the rat striatum during in vivo ischemia. Neurochem. Int. 47, 442-448. doi: 10.1016/j.neuint. 2005.05.014

Michaud, J. P., Bellavance, M. A., Préfontaine, P., and Rivest, S. (2013). Real-time in vivo imaging reveals the ability of monocytes to clear vascular amyloid-beta. Cell Rep. 5, 646-653. doi: 10.1016/j.celrep.2013.10.010

Monif, M., Reid, C. A., Powell, K. L., Smart, M. L., and Williams, D. A. (2009). The $\mathrm{P} 2 \mathrm{X} 7$ receptor drives microglial activation and proliferation: a trophic role for P2X7R pore. J. Neurosci. 29, 3781-3791. doi: 10.1523/JNEUROSCI.5512-08. 2009

Montagne, A., Zhao, Z., and Zlokovic, B. V. (2017). Alzheimer's disease: a matter of blood-brain barrier dysfunction? J. Exp. Med. 214, 3151-3169. doi: 10.1084/ jem.20171406

Mori, T., Wang, X., Aoki, T., and Lo, E. H. (2002). Downregulation of matrix metalloproteinase- 9 and attenuation of edema via inhibition of ERK mitogen activated protein kinase in traumatic brain injury. J. Neurotrauma 19, 14111419. doi: $10.1089 / 089771502320914642$

Mueller, B. K. (2014). Axon growth inhibition by RhoA / ROCK in the central nervous system. Front Neurosci. 8:338. doi: 10.3389/fnins.2014.00338

Muraille, E., Leo, O., and Moser, M. (2014). Th1/Th2 paradigm extended: macrophage polarization as an unappreciated pathogen-driven escape mechanism? Front. Immunol. 5:603. doi: 10.3389/fimmu.2014.00603

Murphy, ÁC., Lalor, S. J., Lynch, M. A., and Mills, K. H. G. (2010). Infiltration of Th1 and Th17 cells and activation of microglia in the CNS during the course of experimental autoimmune encephalomyelitis. Brain. Behav. Immun. 24, 641-651. doi: 10.1016/j.bbi.2010.01.014

Narcisse, L., Scemes, E., Zhao, Y., Lee, S. C., and Brosnan, C. F. (2005). The cytokine IL-1beta transiently enhances P2X7 receptor expression and function in human astrocytes. Glia 49, 245-258. doi: 10.1002/glia.20110

Nisancioglu, M. H., Wallgard, E., Niaudet, C., He, L., Armulik, A., Genove, G., et al. (2010). Pericytes regulate the blood-brain barrier. Nature 468, 557-561. doi: $10.1038 /$ nature09522

Nitta, T., Hata, M., Gotoh, S., Seo, Y., Sasaki, H., Hashimoto, N., et al. (2001). Sizeselective loosening of the blood-brain barrier in claudin-5-deficient mice. J. Cell Biol. 161, 653-660. doi: 10.1083/jcb.200302070

Oliveira-Giacomelli, Á, Albino, C. M., de Souza, H. D. N., Corrêa-Velloso, J., de Jesus Santos, A. P., Baranova, J., et al. (2019). P2Y6 and P2X7 receptor antagonism exerts neuroprotective/ neuroregenerative effects in an animal model of Parkinson's disease. Front. Cell. Neurosci. 13:476. doi: 10.3389/fncel. 2019.00476 
Oliveira-Giacomelli, Á, Albino, C. M., de Souza, H. D. N., and Ulrich, H. (2020). "Restoring dopamine levels in Parkinson's disease: neuronal pathways, agonists and antiinflammatory agents," in Genetics, Neurology, Behavior, and Diet in Parkinson's Disease, eds C. R. Martin and V. R. Preedy (Amsterdam: Elsevier), 479-493. doi: 10.1016/b978-0-12-815950-7.00030-8

Panenka, W., Jijon, H., Herx, L. M., Armstrong, J. N., Feighan, D., Wei, T., et al. (2001). P2X7-like receptor activation in astrocytes increases chemokine monocyte chemoattractant protein-1 expression via mitogen-activated protein kinase. J. Neurosci. 21, 7135-7142. doi: 10.1523/jneurosci.21-18-07135.2001

Paolicelli, R. C., Bolasco, G., Pagani, F., Maggi, L., Scianni, M., Panzanelli, P., et al. (2011). Synaptic pruning by microglia is necessary for normal brain development. Science 333, 1456-1458. doi: 10.1126/science.1202529

Pieper, C., Jacqueline, J., Unterberg, M., Schwerdtle, T., and Galla, H. (2014). Brain capillary pericytes contribute to the immune defense in response to cytokines or LPS in vitro. Brain Res. 1550, 1-8. doi: 10.1016/j.brainres.2014.01.004

Pinheiro, M. A. L., Kooij, G., Mizee, M. R., Kamermans, A., Enzmann, G., Lyck, R., et al. (2016). Immune cell trafficking across the barriers of the central nervous system in multiple sclerosis and stroke. Biochim. Biophys. Acta Mol. Basis Dis. 1862, 461-471. doi: 10.1016/j.bbadis.2015.10.018

Polanco, J. C., Li, C., Bodea, L. G., Martinez-Marmol, R., Meunier, F. A., and Gotz, J. (2018). Amyloid-beta and tau complexity - towards improved biomarkers and targeted therapies. Nat. Rev. Neurol. 14, 22-39. doi: 10.1038/nrneurol.2017.162

Polfliet, M. M. J., van de Veerdonk, F., Döpp, E. A., van Kesteren-Hendrikx, E. M. L., van Rooijen, N., Dijkstra, C. D., et al. (2002). The role of perivascular and meningeal macrophages in experimental allergic encephalomyelitis. J. Neuroimmunol. 122, 1-8. doi: 10.1016/S0165-5728(01)00445-3

Polfliet, M. M. J., Zwijnenburg, P. J. G., van Furth, A. M., van der Poll, T., Döpp, E. A., Renardel de Lavalette, C., et al. (2001). Meningeal and perivascular macrophages of the central nervous system play a protective role during bacterial meningitis. J. Immunol. 167, 4644-4650. doi: 10.4049/jimmunol.167. 8.4644

Prinz, M., and Priller, J. (2017). The role of peripheral immune cells in the CNS in steady state and disease. Nat. Neurosci. 20, 136-144. doi: 10.1038/nn.4475

Ransohoff, R. M. (2016). A polarizing question: do M1 and M2 microglia exist. Nat. Neurosci. 19, 987-991. doi: 10.1038/nn.4338

Ratajczak, M. Z., Adamiak, M., Bujko, K., Thapa, A., Pensato, V., Kucia, M., et al. (2020). Innate immunity orchestrates the mobilization and homing of hematopoietic stem/progenitor cells by engaging purinergic signaling-an update. Purinergic Signal. 16, 153-166. doi: 10.1007/s11302-020-09698-y

Ratajczak, M. Z., Mack, A., Bujko, K., Domingues, A., Pedziwiatr, D., Kucia, M., et al. (2019). ATP-Nlrp3 inflammasome-complement cascade axis in sterile brain inflammation in psychiatric patients and its impact on stem cell trafficking. Stem Cell Rev. Rep. 15, 497-505. doi: 10.1007/s12015-019-09888-1

Ribeiro, D. E., Oliveira-Giacomelli, Á, Glaser, T., Arnaud-Sampaio, V. F., Andrejew, R., Dieckmann, L., et al. (2021). Hyperactivation of P2X7 receptors as a culprit of COVID-19 neuropathology. Mol. Psychiatry 26, 1044-1059. doi: 10.1038/s41380-020-00965-3

Rivas-Yáñez, E., Barrera-Avalos, C., Parra-Tello, B., Briceño, P., Rosemblatt, M. V., Saavedra-Almarza, J., et al. (2020). P2x7 receptor at the crossroads of $t$ cell fate. Int. J. Mol. Sci. 21, 1-22. doi: 10.3390/ijms21144937

Rosenberg, G. A. (2009). Matrix metalloproteinases and their multiple roles in neurodegenerative diseases. Lancet Neurol. 8, 205-216. doi: 10.1016/S14744422(09)70016-X

Rossi, B., Angiari, S., Zenaro, E., Budui, S. L., and Constantin, G. (2011). Vascular inflammation in central nervous system diseases: adhesion receptors controlling leukocyte-endothelial interactions. J. Leukoc Biol. 89, 539-556. doi: 10.1189/jlb.0710432

Rubio-Araiz, A., Perez-Hernandez, M., Urrutia, A., Porcu, F., Borcel, E., GutierrezLopez, M. D., et al. (2014). 3,4-Methylenedioxymethamphetamine (MDMA, ecstasy) disrupts blood-brain barrier integrity through a mechanism involving P2X7 receptors. Int. J. Neuropsychopharmacol. 17, 1243-1255. doi: 10.1017/ S1461145714000145

Rucker, H. K., Wynder, H. J., and Thomas, W. E. (2000). Cellular mechanisms of CNS pericytes. Brain Res. Bull. 51, 363-369. doi: 10.1016/S0361-9230(99) 00260-9

Rustenhoven, J., Jansson, D., Smyth, L. C., and Dragunow, M. (2017). Brain pericytes as mediators of neuroinflammation. Trends Pharmacol. Sci. 38, 291304. doi: 10.1016/j.tips.2016.12.001
Saitou, M., Furuse, M., Sasaki, H., Schulzke, J. D., Fromm, M., Takano, H., et al. (2000). Complex phenotype of mice lacking occludin, a component of tight junction strands. Mol. Biol. Cell 11, 4131-4142. doi: 10.1091/mbc.11.12. 4131

Salter, M., and Stevens, B. (2017). Microglia emerge as central players in brain disease. Nat Med 23, 1018-1027. doi: 10.1038/nm.4397

Sanz, J. M., Chiozzi, P., Ferrari, D., Colaianna, M., Idzko, M., Falzoni, S., et al. (2009). Activation of microglia by amyloid \{beta\} requires P2X7 receptor expression. J. Immunol. 182, 4378-4385. doi: 10.4049/jimmunol.0803612

Savio, L. E. B., Mello, P., de, A., da Silva, C. G., and Coutinho-Silva, R. (2018). The P2X7 receptor in inflammatory diseases: angel or demon? Front. Pharmacol. 9:52. doi: 10.3389/fphar.2018.00052

Sborgi, L., Rühl, S., Mulvihill, E., Pipercevic, J., Heilig, R., Stahlberg, H., et al. (2016). GSDMD membrane pore formation constitutes the mechanism of pyroptotic cell death. EMBO J. 35, 1766-1778. doi: 10.15252/embj.201694696

Sengstake, S., Boneberg, E. M., and Illges, H. (2006). CD21 and CD62L shedding are both inducible via P2X7Rs. Int. Immunol. 18, 1171-1178. doi: 10.1093/intimm/ dx1051

Seo, J., Park, J., Kim, K., Won, J., Yeo, H. G., Jin, Y. B., et al. (2020). Chronic infiltration of T lymphocytes into the brain in a non-human primate model of Parkinson's disease. Neuroscience 431, 73-85. doi: 10.1016/j.neuroscience.2020. 01.043

Serrats, J., Schiltz, J. C., García-Bueno, B., van Rooijen, N., Reyes, T. M., and Sawchenko, P. E. (2010). Dual roles for perivascular macrophages in immune-to-brain signaling. Neuron 65, 94-106. doi: 10.1016/j.neuron.2009.11. 032

Sharp, A. J., Polak, P. E., Simonini, V., Lin, S. X., Richardson, J. C., Bongarzone, E. R., et al. (2008). P2X7 deficiency suppresses development of experimental autoimmune encephalomyelitis. J. Neuroinflammation 8, 5-33. doi: 10.1186/ 1742-2094-5-33

Shieh, C. H., Heinrich, A., Serchov, T., van Calker, D., and Biber, K. (2014). P2X7dependent, but differentially regulated release of IL-6, CCL2, and TNF- $\alpha$ in cultured mouse microglia. Glia 62, 592-607. doi: 10.1002/glia.22628

Shiratori, M., Tozaki-Saitoh, H., Yoshitake, M., Tsuda, M., and Inoue, K. (2010). P2X7 receptor activation induces CXCL2 production in microglia through NFAT and PKC/MAPK pathways. J. Neurochem. 114, 810-819. doi: 10.1111/ j.1471-4159.2010.06809.x

Shlosberg, D., Benifla, M., Kaufer, D., and Friedman, A. (2010). Blood-brain barrier breakdown as a therapeutic target in traumatic brain injury. Nat. Rev. Neurol. 6, 393-403. doi: 10.1038/nrneurol.2010.74

Simpson, J. E., Newcombe, J., Cuzner, M. L., and Woodroofe, M. N. (1998). Expression of monocyte chemoattractant protein- 1 and other beta-chemokines by resident glia and inflammatory cells in multiple sclerosis lesions. J. Neuroimmunol. 84, 238-249. doi: 10.1016/s0165-5728(97)00208-7

Sluyter, R., Shemon, A. N., and Wiley, J. S. (2004). Glu 496 to ala polymorphism in the P2X 7 receptor impairs ATP-Induced IL- $1 \beta$ release from human monocytes. J. Immunol. 172, 3399-3405. doi: 10.4049/jimmunol.172.6. 3399

Solle, M., Labasi, J., Perregaux, D. G., Stam, E., Petrushova, N., Koller, B. H., et al. (2001). Altered cytokine production in mice lacking P2X(7) receptors. J. Biol. Chem. 276, 125-132. doi: 10.1074/jbc.M006781200

Song, W. M., and Colonna, M. (2018). The identity and function of microglia in neurodegeneration. Nat. Immunol. 19, 1048-1058. doi: 10.1038/s41590-0180212-1

Spérlagh, B., Köfalvi, A., Deuchars, J., Atkinson, L., Milligan, C. J., Buckley, N. L., et al. (2002). Involvement of P2X7 receptors in the regulation of neurotransmitter release in the rat hippocampus. J. Neurochem. 81, 1196-1211. doi: 10.1046/j.1471-4159.2002.00920.x

Stephenson, J., Nutma, E., van der Valk, P., and Amor, S. (2018). Inflammation in CNS neurodegenerative diseases. Immunology 154, 204-219. doi: 10.1111/imm. 12922

Stojakovic, A., Paz-Filho, G., Arcos-Burgos, M., Licinio, J., Wong, M. L., and Mastronardi, C. A. (2017). Role of the IL-1 pathway in dopaminergic neurodegeneration and decreased voluntary movement. Mol. Neurobiol. 54, 4486-4495. doi: 10.1007/s12035-016-9988-x

Sulzer, D., Alcalay, R. N., Garretti, F., Cote, L., Kanter, E., Agin-Liebes, J. P., et al. (2017). T cells of Parkinson's disease patients recognize $\alpha$-synuclein peptides. Nature. 546, 656-661. doi: 10.1038/nature22815 
Suzuki, T., Hide, I., Ido, K., Kohsaka, S., Inoue, K., and Nakata, Y. (2004). Production and release of neuroprotective tumor necrosis factor by P2X 7 receptor-activated microglia. J. Neurosci. 24, 1-7. doi: 10.1523/JNEUROSCI. 3792-03.2004

Sweeney, M. D., Zhao, Z., Montagne, A., Nelson, A. R., and Zlokovic, B. V. (2019). Blood-brain barrier: from physiology to disease and back. Physiol. Rev. 99, 21-78. doi: 10.1152/physrev.00050.2017

Tang, Y., and Le, W. (2016). Differential roles of M1 and M2 microglia in neurodegenerative diseases. Mol. Neurobiol. 53, 1181-1194. doi: 10.1007/ s12035-014-9070-5

Tay, T. L., Béchade, C., D’Andrea, I., St-Pierre, M. K., Henry, M. S., Roumier, A., et al. (2018). Microglia gone rogue: Impacts on psychiatric disorders across the lifespan. Front. Mol. Neurosci. 10, 1-26. doi: 10.3389/fnmol.2017.00421

Togo, T., Akiyama, H., Iseki, E., Kondo, H., Ikeda, K., Kato, M., et al. (2002). Occurrence of $\mathrm{T}$ cells in the brain of Alzheimer's disease and other neurological diseases. J. Neuroimmunol. 124, 83-92. doi: 10.1016/s01655728(01)00496-9

Toulorge, D., Schapira, A. H. V., and Hajj, R. (2016). Molecular changes in the postmortem parkinsonian brain. J. Neurochem. 139, 27-58. doi: 10.1111/jnc. 13696

Tran, E., Hoekstra, K., van Rooijen, N., Dijkstra, C., and Owens, T. (1998). Immune invasion of the central nervous system parenchyma and experimental allergic encephalomyelitis, but not leukocyte extravasation from blood, are prevented in macrophage-depleted mice. J. Immunol. 161, 3767-3775.

Trapp, B. D., and Nave, K. A. (2008). Multiple sclerosis: an immune or neurodegenerative disorder? Annu. Rev. Neurosci. 31, 247-269. doi: 10.1146/ annurev.neuro.30.051606.094313

Tripathy, D., Thirumangalakudi, L., and Grammas, P. (2010). RANTES upregulation in the Alzheimer's disease brain: a possible neuroprotective role. Neurobiol. Aging 31, 8-16. doi: 10.1016/j.neurobiolaging.2008.03.009

Van Weehaeghe, D., Koole, M., Schmidt, M. E., Deman, S., Jacobs, A. H., Souche, E., et al. (2019). [11C]JNJ54173717, a novel P2X7 receptor radioligand as marker for neuroinflammation: human biodistribution, dosimetry, brain kinetic modelling and quantification of brain P2X7 receptors in patients with Parkinson's disease and healthy volunteers. Eur. J. Nucl. Med. Mol. Imaging 46, 2051-2064. doi: 10.1007/s00259-019-04369-6

Vargas-Martínez, E. M., Gómez-Coronado, K. S., Espinosa-Luna, R., ValdezMorales, E. E., Barrios-García, T., Barajas-Espinosa, A., et al. (2020). Functional expression of $\mathrm{P} 2 \mathrm{X} 1, \mathrm{P} 2 \mathrm{X} 4$ and $\mathrm{P} 2 \mathrm{X} 7$ purinergic receptors in human monocytederived macrophages. Eur. J. Pharmacol. 888:173460. doi: 10.1016/j.ejphar. 2020.173460

Vasilache, A. M., Qian, H., and Blomqvist, A. (2015). Immune challenge by intraperitoneal administration of lipopolysaccharide directs gene expression in distinct blood-brain barrier cells toward enhanced prostaglandin E2 signaling. Brain Behav. Immun. 48, 31-41. doi: 10.1016/j.bbi.2015.02.003

Vecil, G. G., Larsen, P. H., Corley, S. M., Herx, L. M., Besson, A., Goodyer, C. G., et al. (2000). Interleukin-1 is a key regulator of matrix metalloproteinase-9 expression in human neurons in culture and following mouse brain trauma in vivo. J. Neurosci. Res. 61, 212-224. doi: 10.1002/1097-4547(20000715)61: $2<212:$ :aid-jnr12>3.0.co;2-9

Voet, S., Srinivasan, S., Lamkanfi, M., and Loo, G. (2019). Inflammasomes in neuroinflammatory and neurodegenerative diseases. ЕMBO Mol. Med. 11, 1-16. doi: 10.15252/emmm.201810248

Volonte, C., Amadio, S., Cavaliere, F., D'Ambrosi, N., Vacca, F., and Bernardi, G. (2003). Extracellular ATP and neurodegeneration. Curr. Drug Targets CNS Neurol. Disord. 2, 403-412. doi: 10.2174/1568007033482643

Wang, X., and Sanz, L. (2016). Immune regulation by pericytes: modulating innate and adaptive immunity. Front. Immunol. 7:480. doi: 10.3389/fimmu. 2016.00480

Wanhainen, K. M., Jameson, S. C., and da Silva, H. B. (2019). Self-Regulation of memory CD8 T cell metabolism through extracellular ATP signaling. Immunometabolism 1:e190009. doi: 10.20900/immunometab20190009

Wesselius, A., Bours, M. J. L., Arts, I. C. W., Theunisz, E. H. E., Geusens, P., and Dagnelie, P. C. (2012). The P2X7 loss-of-function Glu496Ala polymorphism affects ex vivo cytokine release and protects against the cytotoxic effects of high ATP-levels. BMC Immunol. 13:64. doi: 10.1186/1471-2172-13-64

Wiley, J. S., and Gu, B. J. (2012). A new role for the P2X7 receptor: a scavenger receptor for bacteria and apoptotic cells in the absence of serum and extracellular ATP. Purinergic Signal. 8, 579-586. doi: 10.1007/s11302-0129308-5
Willis, C. L., Garwood, C. J., and Ray, D. E. (2007). A size selective vascular barrier in the rat area postrema formed by perivascular macrophages and the extracellular matrix. Neuroscience 150, 498-509. doi: 10.1016/j.neuroscience. 2007.09.023

Winkler, E. A., Bell, R. D., and Zlokovic, B. V. (2011). Central nervous system pericytes in health and disease. Nat. Neurosci. 14, 1398-1405. doi: 10.1038/nn. 2946

Witting, A., Chen, L., Cudaback, E., Straiker, A., Walter, L., Rickman, B., et al. (2006). Experimental autoimmune encephalomyelitis disrupts endocannabinoid-mediated neuroprotection. Proc. Natl. Acad. Sci. U.S.A. 103, 6362-6367. doi: 10.1073/pnas.0510418103

Xu, X. J., Boumechache, M., Robinson, L. E., Marschall, V., Gorecki, D. C., Masin, M., et al. (2012). Splice variants of the P2X7 receptor reveal differential agonist dependence and functional coupling with pannexin-1. J. Cell Sci. 125, 3776-3789. doi: 10.1242/jcs.099374

Xu, Z., Chen, Z. M., Wu, X., Zhang, L., Cao, Y., and Zhou, P. (2020). Distinct molecular mechanisms underlying potassium efflux for NLRP3 inflammasome activation. Front. Immunol. 11:9441. doi: 10.3389/fimmu.2020.609441

Yamasaki, R., Lu, H., Butovsky, O., Ohno, N., Rietsch, A. M., Cialic, R., et al. (2014). Differential roles of microglia and monocytes in the inflamed central nervous system. J. Exp. Med. 211, 1533-1549. doi: 10.1084/jem.20132477

Yang, F., Zhao, K., Zhang, X., Zhang, J., and Xu, B. (2016). ATP induces disruption of tight junction proteins via IL-1 beta-dependent MMP-9 activation of human blood-brain barrier in vitro. Neural Plast. 2016:8928530. doi: 10.1155/2016/ 8928530

Yiangou, Y., Facer, P., Durrenberger, P., Chessell, I. P., Naylor, A., Bountra, C., et al. (2006). COX-2, CB2 and P2X7-immunoreactivities are increased in activated microglial cells/macrophages of multiple sclerosis and amyotrophic lateral sclerosis spinal cord. BMC Neurol. 6:12. doi: 10.1186/1471-2377-6-12

Yip, L., Woehrle, T., Corriden, R., Hirsh, M., Chen, Y., Inoue, Y., et al. (2009). Autocrine regulation of $\mathrm{T}-$ cell activation by ATP release and $\mathrm{P} 2 \mathrm{X} 7$ receptors. FASEB J. 23, 1685-1693. doi: 10.1096/fj.08-126458

Zenaro, E., Pietronigro, E., Della Bianca, V., Piacentino, G., Marongiu, L., Budui, S., et al. (2015). Neutrophils promote Alzheimer's disease-like pathology and cognitive decline via LFA-1 integrin. Nat. Med. 21, 880-886. doi: 10.1038/nm. 3913

Zhang, Z., Zhang, Z. Y., Schittenhelm, J., Wu, Y., Meyermann, R., and Schluesener, H. J. (2011). Parenchymal accumulation of $\mathrm{CD} 163^{+}$macrophages/microglia in multiple sclerosis brains. J. Neuroimmunol. 237, 73-79. doi: 10.1016/j.jneuroim. 2011.06.006

Zhao, H., Zhang, X., Dai, Z., Feng, Y., Li, Q., Zhang, J. H., et al. (2016). $\mathrm{P} 2 \mathrm{X} 7$ receptor suppression preserves blood-brain barrier through inhibiting RhoA activation after experimental intracerebral hemorrhage in rats. Sci. Rep. 6:23286.

Zhao, Z., Nelson, A. R., Betsholtz, C., and Zlokovic, B. V. (2015). Perspective establishment and dysfunction of the blood-brain barrier. Cell 163, 1064-1078. doi: 10.1016/j.cell.2015.10.067

Zhao, Z., Wang, Y., Zhou, R., Li, Y., Gao, Y., Tu, D., et al. (2020). A novel role of NLRP3-generated IL-1 $\beta$ in the acute-chronic transition of peripheral lipopolysaccharide-elicited neuroinflammation: implications for sepsis-associated neurodegeneration. J. Neuroinflammation 17, 1-19. doi: 10. 1186/s12974-020-1728-5

Zlokovic, B. V. (2011). Neurovascular pathways to neurodegeneration in Alzheimer's disease and other disorders. Nat. Rev. Neurosci. 12, 723-738. doi: 10.1038/nrn3114

Zumerle, S., Calì, B., Munari, F., Angioni, R., Di Virgilio, F., Molon, B., et al. (2019). Intercellular calcium signaling induced by ATP potentiates macrophage phagocytosis. Cell Rep. 27, 1-10.e4. doi: 10.1016/j.celrep.2019.03.011

Conflict of Interest: The authors declare that the research was conducted in the absence of any commercial or financial relationships that could be construed as a potential conflict of interest.

Copyright (C) 2021 Oliveira-Giacomelli, Petiz, Andrejew, Turrini, Silva, Sack and Ulrich. This is an open-access article distributed under the terms of the Creative Commons Attribution License (CC BY). The use, distribution or reproduction in other forums is permitted, provided the original author(s) and the copyright owner(s) are credited and that the original publication in this journal is cited, in accordance with accepted academic practice. No use, distribution or reproduction is permitted which does not comply with these terms. 